\title{
Transcriptome profiling of the feeding-to-fasting transition in chicken liver
}

\author{
Colette Désert ${ }^{1,2}$, Michel J Duclos ${ }^{3}$, Pierre Blavy ${ }^{1,2}$, Frédéric Lecerf ${ }^{1,2}$, \\ François Moreews ${ }^{4}$, Christophe Klopp ${ }^{5}$, Marc Aubry ${ }^{6}$, Frédéric Herault 1,2 , \\ Pascale Le Roy ${ }^{1,2}$, Cécile Berri ${ }^{3}$, Madeleine Douaire ${ }^{1,2}$, Christian Diot ${ }^{1,2}$ and \\ Sandrine Lagarrigue*1,2
}

Address: ${ }^{1}$ INRA, UMR 598, Génétique Animale, F-35000 Rennes, France, ${ }^{2}$ Agrocampus Ouest, UMR 598, Génétique Animale, F-35000 Rennes, France, ${ }^{3}$ INRA, UR83, Station de Recherches Avicoles, F-37380 Nouzilly, France, ${ }^{4}$ INRA, SIGENAE, F-35000 Rennes, France, ${ }^{5}$ INRA, SIGENAE, F31000 Toulouse, France and 'Plateforme Transcriptome OUEST-genopole Rennes, F-35000 Rennes, France

Email: Colette Désert - colette.desert@agrocampus-rennes.fr; Michel J Duclos - michel.duclos@tours.inra.fr; Pierre Blavy - pierre.blavy@irisa.fr; Frédéric Lecerf - frederic.lecerf@agrocampus-rennes.fr; François Moreews - francois.moreews@irisa.fr;

Christophe Klopp - Christophe.Klopp@toulouse.inra.fr; Marc Aubry - marc.aubry@univ-rennes1.fr;

Frédéric Herault - frederic.herault@rennes.inra.fr; Pascale Le Roy - pascale.leroy@rennes.inra.fr; Cécile Berri - cecile.berri@tours.inra.fr;

Madeleine Douaire - madeleine.douaire@rennes.inra.fr; Christian Diot - christian.diot@rennes.inra.fr;

Sandrine Lagarrigue* - sandrine.lagarrigue@agrocampus-rennes.fr

* Corresponding author

Published: 17 December 2008

BMC Genomics 2008, 9:6II doi:10.1|86/|47|-2164-9-6II
Received: 25 August 2008

Accepted: 17 December 2008

This article is available from: http://www.biomedcentral.com/I47I-2164/9/6II

(c) 2008 Désert et al; licensee BioMed Central Ltd.

This is an Open Access article distributed under the terms of the Creative Commons Attribution License (http://creativecommons.org/licenses/by/2.0), which permits unrestricted use, distribution, and reproduction in any medium, provided the original work is properly cited.

\begin{abstract}
Background: Starvation triggers a complex array of adaptative metabolic responses including energy-metabolic responses, a process which must imply tissue specific alterations in gene expression and in which the liver plays a central role. The present study aimed to describe the evolution of global gene expression profiles in liver of 4-week-old male chickens during a $48 \mathrm{~h}$ fasting period using a chicken $20 \mathrm{~K}$ oligoarray.

Results: A large number of genes were modulated by fasting ( 3532 genes with a pvalue corrected by Benjamini-Hochberg < 0.01); 2062 showed an amplitude of variation higher than $+/-40 \%$ among those, 1162 presented an human ortholog, allowing to collect functional information. Notably more genes were down-regulated than up-regulated, whatever the duration of fasting ( $16 \mathrm{~h}$ or $48 \mathrm{~h})$. The number of genes differentially expressed after $48 \mathrm{~h}$ of fasting was 3.5 -fold higher than after $16 \mathrm{~h}$ of fasting. Four clusters of co-expressed genes were identified by a hierarchical cluster analysis. Gene Ontology, KEGG and Ingenuity databases were then used to identify the metabolic processes associated to each cluster. After $16 \mathrm{~h}$ of fasting, genes involved in ketogenesis, gluconeogenesis and mitochondrial or peroxisomal fatty acid beta-oxidation, were up-regulated (cluster-I) whereas genes involved in fatty acid and cholesterol synthesis were down-regulated (cluster-2). For all genes tested, the microarray data was confirmed by quantitative RT-PCR. Most genes were altered by fasting as already reported in mammals. A notable exception was the HMG-CoA synthase I gene, which was up-regulated following 16 and $48 \mathrm{~h}$ of fasting while the other genes involved in cholesterol metabolism were down-regulated as reported in mammalian studies. We further focused on genes not represented on the microarray and candidates for the regulation of the target
\end{abstract}


genes belonging to cluster-I and -2 and involved in lipid metabolism. Data are provided concerning PPARa, SREBPI, SREBP2, NRIH3 transcription factors and two desaturases (FADSI, FADS2).

Conclusion: This study evidences numerous genes altered by starvation in chickens and suggests a global repression of cellular activity in response to this stressor. The central role of lipid and acetyl-CoA metabolisms and its regulation at transcriptional level are confirmed in chicken liver in response to short-term fasting. Interesting expression modulations were observed for $\mathrm{NRIH3}$, FADSI and FADS2 genes. Further studies are needed to precise their role in the complex regulatory network controlling lipid metabolism.

\section{Background}

All animal species have evolved a metabolic response system allowing them to survive during periods of energy deprivation. The overall metabolic response to fasting operates at numerous levels and has been relatively well characterized in mammals [1-6]. In vertebrates, the liver plays a central role in this adaptive response. Deprivation of food inhibits lipogenesis and induces the release of large amounts of fatty acids from the adipose tissue, which are taken up by the liver and oxidized in the peroxisome and/or mitochondria via beta-oxidation. The majority of fatty acids are only partially oxidized to acetylcoenzyme A (acetyl-CoA), which then condenses with itself to form ketone bodies, an important fuel for the brain. The energy released in the process of beta-oxidation is used by the liver to carry out gluconeogenesis from substrates such as glycerol, lactate, and amino acids.

Several studies showed that the inhibition of fatty acid synthesis and the induction of gluconeogenesis, ketogenesis and fatty acid beta-oxidation in response to fasting result from changes in mRNA level of genes encoding enzymes and transcription regulators involved in these metabolisms [6]. Several studies using PPARa-null mice [7-9] have demonstrated a key role of PPARa in this response. Although microarray-based experiments have been widely used to identify differentially expressed genes involved in numerous biological processes, only few studies have considered the effect of fasting on large-scale hepatic gene profiles. Data are available in the mouse $[10,11]$, the pig [12] (but the study was limited to 1272 cDNA) and more recently the rainbow trout [13] and the rat [14]. In the present study, the chicken species was chosen as an important model organism that bridges the evolutionary gap between mammals and other vertebrates; a divergence that occurred about 300 million years ago. Previous studies have shown that the activities or expression of hepatic enzymes involved in lipogenesis, beta-oxidation and gluconeogenesis (ME, ACLY, ACACA [15]; CPT1A, EHHADH [16]; PEPCK [17]) and plasma metabolites and hormones levels (Glucose, lactate, pyruvate, aceto-acetate, B-hydroxybutyrate [17]; Insulin [18]) were altered during fasting in chickens. Overall the available data show that chickens share most metabolic responses with mammals despite some distinct features. In birds lipogenesis occurs essentially in the liver [19-21] contrary to rodents or pigs in which it is regulated in both liver and adipose tissue. Regulation of gluconeogenesis differs too, essentially due to intracellular location of key enzymes [22]. Chicken plasma metabolites have different levels from those reported for mammals, especially glucose which is higher. To extend and complete previous studies conducted on candidate genes, the present study aimed to describe the evolution of global gene expression profiles in chicken liver during a $48 \mathrm{~h}$ fasting period by using pangenomic oligo microarrays. The second reason to choose chicken as model is that this species provides a major protein source from meat throughout the world and the excessive accumulation of lipids in birds is one of the main problems facing this industry. To our knowledge, no whole genome survey of hepatic gene expression has been reported in chickens so far [23]. The use of a recently available $20 \mathrm{~K}$ oligo microarray allowed us to make the first description of the alteration of hepatic gene profiles induced by fasting in this species and make some hypothesis on the regulatory mechanisms involved at the mRNA level. The genes showing a significant alteration in their expression profile during fasting were grouped in four clusters of co-expressed genes by a two-way Hierarchical Clustering Analysis. Further interpretation was based on the use of different gene annotation databases (GO, KEGG and Ingenuity databases) highlighting numerous biological processes modulated by fasting.

\section{Results \\ Experimental and microarray setup}

To evaluate the changes in hepatic gene expression in response to starvation, 4 week-old male chickens were submitted to $0,16 \mathrm{~h}$ or $48 \mathrm{~h}$ of food withdrawal. Transcriptome profiling of these "Fed", "Fst16" and "Fst48" nutritional stages was carried out by using a $20 \mathrm{~K}$ microarray. The expression data of the 20460 gene set from 18 independent oligochips was normalized by "Lowess-fitness". Of the 20460 oligos present on the microarray, 13057 aligning with a unique coding region of the 2.1 Washington University assembly of the chicken sequence genome, were chosen for statistical analyses. The expression data were further analyzed by analysis of variance 
with the eBayes procedure [24] using LIMMA package (see Methods) to identify differentially expressed genes between either of the two fasting states and the fed state. Clusters of co-expressed genes were identified by two-way Hierarchical Cluster Analysis and the degree of importance of each gene in this cluster identification was explored by Principal Component Analysis. Gene Ontology, KEGG and INGENUITY databases were used for further interpretation, as 7419 genes (out of 13057) presented a human ortholog with a HUGO symbol allowing us to recover functional annotations from those databases.

The microarray data results were deposited in the Gene Expression Omnibus (GEO) public repository http:// www.ncbi.nlm.nih.gov/geo. The accession number for the series is GSE11290 and the sample series can be retrieved with accession number GSM278021, GSM282110, and GSM284914 up to GSM284948. The sample series contains for each microarray the raw data (median signal) of each Cy5 and Cy3 channels as well as the normalized data $(\log 2($ ratio Cy5/Cy3))

\section{A high number of genes differentially expressed between the two fasting states and the Fed state}

A high number of gene transcripts were significantly altered by fasting, so that we considered only those presenting an amplitude of variation higher than $+/-40 \%$ between fasting and fed conditions (Figure 1A). The percentage of genes presenting such a modulation increased lower pvalues were choosen, for example for a cut-off fixed to 1.4 , it increased from $58 \%$ with a pvalue of 0.01 to $95 \%$ with a pvalue of 0.0001 . In the present study, the 2062 genes that satisfied the criterion of pvalue $<0.01$ and absolute fold-change $>1.4$ were considered for further analysis. Among these genes, the number of regulated genes was 3.5-fold higher after $48 \mathrm{~h}$ of fasting than after $16 \mathrm{~h}$. We further performed a global analysis of the 1162 genes fulfilling those conditions and for which annotation could be retrieved through their human ortholog (Figure 1-B). The selected 0.01 pvalue that was corrected according to the false discovery rate (FDR) of BenjaminiHochberg [25] ensures in average a number of false positive of 12 genes in this selected gene set. In this set, 190 genes were altered after $16 \mathrm{~h}$ of fasting, 777 after $48 \mathrm{~h}$ of

\begin{tabular}{|c|c|c|c|}
\hline \multirow[t]{2}{*}{$A$} & \multicolumn{3}{|c|}{ pvalue } \\
\hline & 0.0001 & 0.001 & 0.01 \\
\hline $\begin{array}{l}\text { Number of gene-oligo differentially expressed between Fed } \\
\text { and the two fasting states }\end{array}$ & 921 & 1825 & 3532 \\
\hline Absolute (fold change) $>=2$ & $38 \%$ & $19 \%$ & $11 \%$ \\
\hline Absolute (fold change) $>=1.4$ & $95 \%$ & $80 \%$ & $58 \%$ \\
\hline $\begin{array}{l}\text { Number of gene-oligo with an absolute expression } \\
\text { modulation }>=1.4\end{array}$ & 873 & 1463 & 2062 \\
\hline Fst16-Fed & 128 & 223 & 391 \\
\hline Fst48-Fed & 668 & 1089 & 1421 \\
\hline Fst16-Fed and Fst48-Fed & 77 & 151 & 250 \\
\hline $\begin{array}{l}\text { Number of gene-oligo with an identified human ortholog } \\
\text { whose HUGO symbol was available }\end{array}$ & 509 & 836 & 1162 \\
\hline $\begin{array}{l}\text { Fst } 16 \text { - Fed: } \\
385 \text { genes }\end{array}$ & $\begin{array}{r}\text { Fst } \\
972\end{array}$ & ed: & \\
\hline
\end{tabular}

Figure I

Genes differentially expressed between Fed and the two fasting Fst 16 and Fst48 states. A: Number of genes differentially expressed according to the pvalues corrected by Benjamini-Hochberg. B: Venn diagram for the genes differentially expressed (pvalue $<0.01$ ) in the two contrasts "I 6 h of fasting versus the fed state" (Fst l6-Fed) and " 48 h of fasting versus the fed state" (Fst48-Fed). 
fasting, and 195 after $16 \mathrm{~h}$ and $48 \mathrm{~h}$ (with the concordant variations for 190 of them).

A two-way Hierarchical Cluster Analysis (HCA) was applied to the normalized dataset to identify clusters among the 18 animals and these 1162 genes (Figure 2). As expected, the animal dendrogram clearly separated the three nutritional conditions: the Fst 48 state was more distant from the Fed state than the Fst16 state. The dendrogram also showed a higher homogeneity between individuals intra than inter nutritional conditions, showing that the number of chickens analyzed by condition was appropriate for such a study.

For the gene variables, four clusters were identified. The clusters 1 (277 genes) and 2 (95 genes) were respectively down- and up-regulated after $16 \mathrm{~h}$ of fasting. The majority of genes in cluster $1(66 \%)$ were also significantly downregulated after $48 \mathrm{~h}$ of fasting, but with an amplitude similar to that observed after $16 \mathrm{~h}$. The majority of genes in cluster $2(71 \%)$ returned to fed levels by $48 \mathrm{~h}$ of fasting.
The clusters 3 (517 genes) and 4 (273 genes) corresponded to the genes respectively down- and up-regulated only after $48 \mathrm{~h}$ of fasting. Altogether, the number of genes significantly down-regulated by fasting was higher than the number of genes up-regulated: 799 versus 360 genes. Only 3 genes (TMEM43, AP3B2, C1orf59) were regulated in an opposite way between the Fst16 and Fst48 states. The list of the 1162 significantly differentially expressed genes with the associated cluster is presented in an additional file 1.

In complement to the HCA, Principal Components Analysis (PCA) allowed to identify the genes contributing most to the separation of individuals. The first two components of PCA (explaining $70 \%$ of the total variability) clearly separated the three nutritional conditions (Figure $3-\mathrm{A}$ ) and about $80 \%$ of the genes showed a high correlation with the two principal components $(>0.7)$ (Figure 3$B)$. Further analysis of the whole dataset was then considered to identify the main biological processes regulated by fasting.

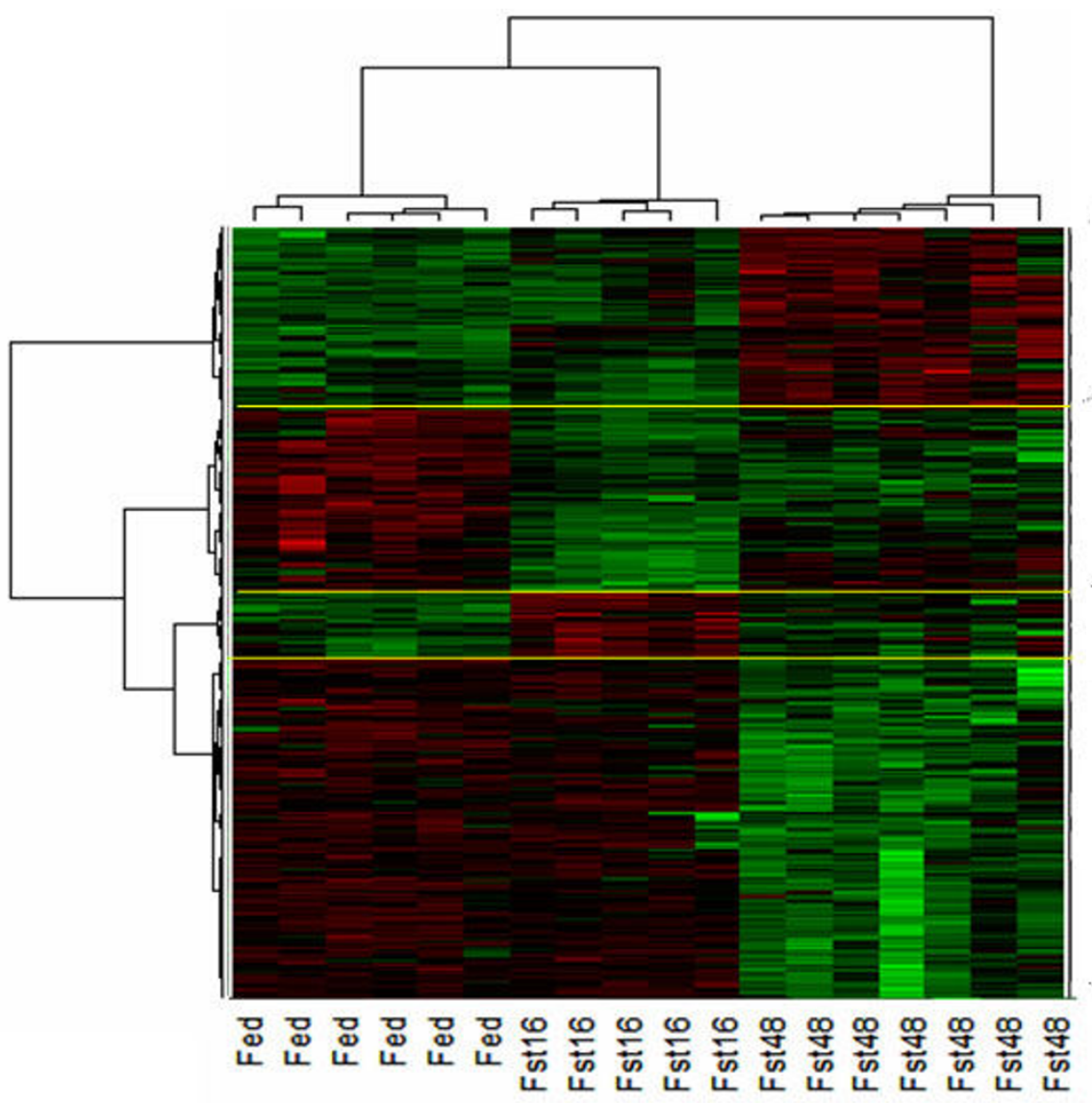

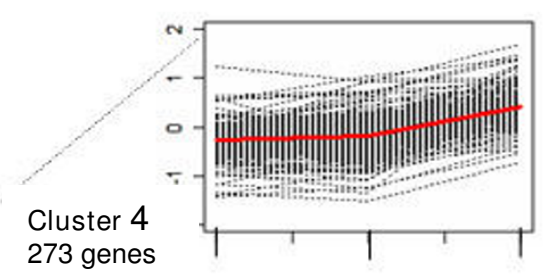
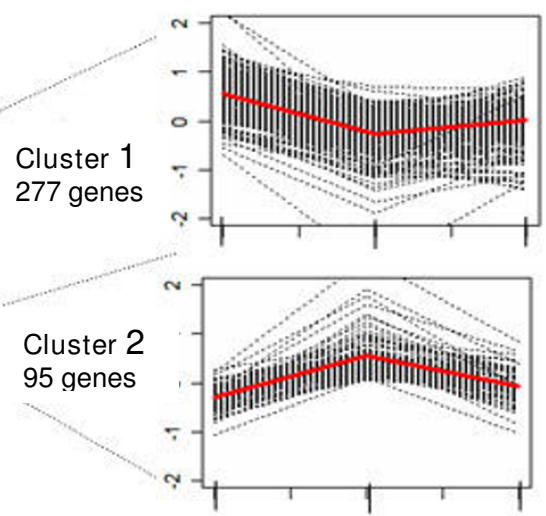

Cluster 3 517 genes

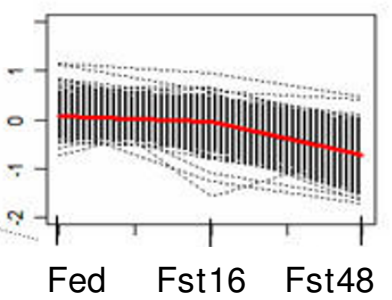

\section{Figure 2}

Two-way Hierarchical Cluster Analysis (HCA) of the gene selection. On the right, for each cluster, the curves of the expression of all the genes corresponding to the three nutritional states (the mean curve is in red). 

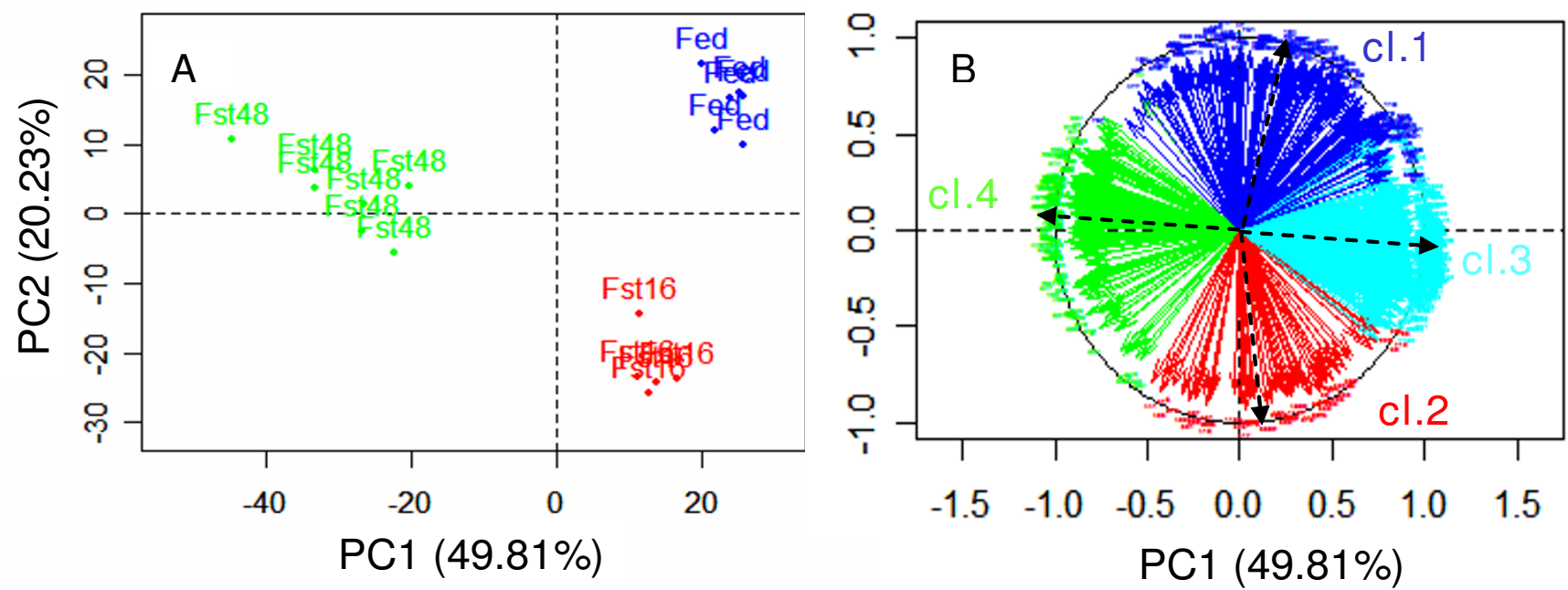

Figure 3

Principal Component Analysis (PCA) of the gene selection. The gene variables for the PCA were scaled to give them the same importance. A: individual factor map; B: gene factor map, only the genes highly correlated to the first two components are indicated $(r>0.7)$. The gene color was determined according to their HCA cluster $(c l . i=$ cluster $\mathrm{i})$.

\section{Annotation of gene clusters using Gene Ontology (GO), KEGG and Ingenuity databases}

Gene ontology (GO) terms have been widely used as a tool for a global interpretation of microarray data. Table 1 indicates the biological process GO terms enriched for each of the 4 clusters obtained by HCA (pvalue < 0.01). The most over-represented GO terms (high pvalue and at least 3 genes associated to the term) concerned "lipid biosynthesis", "fatty acid biosynthesis" corresponding to genes down-regulated after $16 \mathrm{~h}$ of fasting (cluster 1 ) and "fatty acid beta-oxidation" and "gluconeogenesis" corresponding to genes up-regulated after $16 \mathrm{~h}$ of fasting (cluster 2). These observations were consistent with those already reported in mammals.

Among the enriched GO terms of the cluster 3 (down-regulated after $48 \mathrm{~h}$ of fasting only) were "glycolysis", "regulation of protein catabolism" and surprisingly "cell cycle" with more than 30 genes associated. Of the six genes associated with "Glycolysis", PKM2 encodes a pyruvate kinase that catalyses an irreversible reaction in glycolysis. ATE1 and MDM2, two genes annotated as involved in the "regulation of protein catabolism" are part of the ubiquitinproteasome system. No enriched GO terms was found for the cluster 4 .

The biological interpretation of the gene clusters was further completed using KEGG database [26] and Ingenuity Pathway Analysis (IPA, Ingenuity Systems Inc., Redwood City, CA). The significant KEGG and IPA pathways are indicated in Table 1 with the genes associated. IPA and
Kegg pathway analyses highlighted some biological processes already revealed by GO analysis, plus other ones, showing the interest in combining different sources of annotation. Cluster 1, down-regulated at $16 \mathrm{~h}$ of fasting, was mainly characterized by genes involved in cholesterol metabolism and fatty acid biosynthesis, through the annotation terms "lipid metabolism", "lipid biosynthesis", "carboxylic acid biosynthesis", "fatty acid biosynthesis". Lipogenic genes (ACACA, FASN, SCD, ACLY), cholesterogenic genes (CYP51A1, LSS) and genes involved in triglyceride synthesis (DGAT2L4, ANGPTL2) were found in the list. Cluster 2, up-regulated at $16 \mathrm{~h}$ of fasting, was essentially characterized by genes involved in fatty acid metabolism/oxidation and acetyl-CoA metabolism through the annotation terms "fatty acid beta-oxydation", "energy derivation by oxidation of organic compounds", "gluconeogenesis", "PPAR signalling pathway", "synthesis and degradation of ketone bodies", "citrate cycle TCA cycle" and "pyruvate metabolism". The list comprised genes involved in fatty acid beta-oxidation (PECI, ACAA1, ACOX1, CPT1A, HADHA), ketogenesis (HMGCL, ACAT1), gluconeogenesis (PCK1, FBP1, FBP2) and fatty acid transport or activation (ACSL1, APOB, $F A B P 1$ ). Cluster 3, down-regulated at $48 \mathrm{~h}$ of fasting, was essentially characterized by genes involved in "glycolysis" (6 genes), "cell cycle" (more than 30 genes associated to this GO term) and 12 signalling pathways including "Insulin signaling pathway" and "Estrogen Receptor Signaling". Cluster 4, up-regulated at $48 \mathrm{~h}$ of fasting, was associated to various annotation terms, notably "cAMPmediated Signaling" linked to glucagon/insulin balance. 
Table I: Annotation of gene clusters using Gene Ontology (GO), KEGG and Ingenuity databases

\begin{tabular}{|c|c|c|c|}
\hline & Biological process GO terms I & KEGG pathways ${ }^{2}$ & Ingenuity pathways ${ }^{3}$ \\
\hline Cluster I & $\begin{array}{l}\text { Lipid metabolism } \\
\text { SLC27A4 -LYPLA2-ENPP6-DGAT2L4-CYP5IAI-FASN- } \\
\text { SULT4AI-CPNE7-ANGPTL3-ACACA-LSS-ACLY-PBXI- } \\
\text { PIGH-PLCLI-PRKAG3-PRKAA2-SCD -SBF2-PLA2G I2B- } \\
\text { MTMR3-PITPNMI } \\
P=5 . E-04\end{array}$ & $\begin{array}{l}\text { Fatty acid biosynthesis } \\
A C L Y-F A S N-A C A C A-S C D\end{array}$ & $\frac{\text { Fatty Acid Biosynthesis }}{\text { FASN-ACACA-MCCC2 P }}=5 . E-04$ \\
\hline 277 genes & $\begin{array}{l}\text { Lipid biosynthesis } \\
\text { DGAT2L4-CYP5IAI-FASN-ACACA-LSS-ACLY-PBXI- } \\
\text { PIGH-PRKAG3-PRKAA2-SCD P = } 2 . E-03 \\
\text { Fatty acid biosynthesis } \\
\text { FASN-ACACA-PRKAG3-PRKAA2-SCD } \\
P=6 . E-03 \\
\text { Regulation of action potential } \\
\text { KCNMB2-SBF2-EIF2B4 P = 7.E-03 }\end{array}$ & & \\
\hline $\begin{array}{l}\text { Cluster } 2 \\
95 \text { genes }\end{array}$ & $\begin{array}{l}\text { Lipid metabolism } \\
\text { PECI-DCTN6-CPTIA-FABPI-ACSLI-ACAAI-HADHA- } \\
\text { HMGCSI-APOB-ACOXI-SCP2-ADIPOR2-PLCZI } \\
P=3 . E-06 \\
\text { Fatty acid metabolism } \\
\text { PECI-CPTIA-FABPI-ACSLI-ACAAI-HADHA-ACOXI- } \\
\text { ADIPOR2 P = } 2 . E-07 \\
\text { Fatty acid oxidation } \\
\text { CPTIA-HADHA-ACOXI-ADIPOR2 } \\
P=4 . E-06 \\
\text { Fatty acid beta-oxidation } \\
\text { CPTIA-HADHA-ACOXI P = 2.E-05 } \\
\text { Energy derivation by oxidation of organic } \\
\text { compounds } \\
\text { FBPI-IDHI-PCKI-FBP2-GYG2 } \\
P=8 . E-03 \\
\text { Gluconeogenesis } \\
\text { FBPI-PCKI-FBP2 P }=4 . E-04\end{array}$ & $\begin{array}{l}\text { Fatty acid metabolism } \\
\text { ACATI-PECI-ACAAI-ACOXI- } \\
\text { HADHA-ACSLI } \\
\text { PPAR signalling pathway } \\
\text { PCKI-SCP2-FABPI-ACAAI-ACOXI- } \\
\text { ACSLI } \\
\text { Synthesis and degradation of } \\
\text { ketone bodies } \\
\text { ACATI-HMGCL-ACAAI-HMGCSI } \\
\text { Citrate cycle TCA cycle } \\
\text { PCKI-ACATI-HMGCL-IDHI-ACAAI } \\
\text { Gluconeogenesis } \\
\text { PCKI-ACATI-HMGCL-FBPI } \\
\text { Valine.leucine and isoleucine } \\
\text { degradation } \\
\text { ACATI-HMGCL-ACAAI-HADHA- } \\
\text { HMGCSI } \\
\text { Lysine degradation } \\
\text { ACATI-BBOXI-HADHA }\end{array}$ & $\begin{array}{l}\text { Fatty Acid Metabolism } \\
\text { CYP3A43-CYP4A22-CPTIA-ACAAI-CYP2CI8-ACOXI-PECI- } \\
\text { ACATI-ACSLI-HADHA P = 2.E-II } \\
\text { Synthesis and Degradation of Ketone Bodies } \\
\text { I-06EOI 6-42E-02 CYP3A43-CYP4A22-CPTIA-ACAAI-CYP2CI 8- } \\
\text { ACOXI-PECI-CPT2-ACATI-EHHADH-ACSLI-HADHA } \\
\text { ACAAI-ACATI-HMGCL-HMGCSI-HADHA P = 2.E-II } \\
\text { Pyruvate Metabolism } \\
\text { ACAAI-ACATI-PCKI-ACSLI-HADHA } \\
\text { P = 2.E-05 } \\
\text { Valine- Leucine and Isoleucine Degradation } \\
\text { ACAAI-ACATI-HMGCL-HMGCSI-HADHA P = 9.E-08 6-94E00 6- } \\
\text { 54E-02 ACAAI-ACATI-HMGCL-HMGCS2-EHHADH-HMGCSI- } \\
\text { HADHA } \\
\text { Lysine Degradation } \\
\text { BBOXI-ACAAI-ACATI-MLL3-HADHA } \\
\text { P = I.E-06 } \\
\text { Tryptophan Metabolism } \\
\text { CYP3A43-CYP4A22-ACAAI-CYP2CI8-ACATI-HADHA P = 8.E-06 } \\
\text { Propanoate Metabolism } \\
\text { ACAAI-ACATI-ACSLI-HADHA } \\
\text { P = I.E-05 I-36E00 2-02E-02 EHHADH-HADHA 8-54E-0I I-69E-02 } \\
\text { PCKI-IGFBPI }\end{array}$ \\
\hline
\end{tabular}




\begin{tabular}{|c|c|c|c|}
\hline $\begin{array}{l}\text { Cluster } 3 \\
517 \text { genes }\end{array}$ & $\begin{array}{l}\text { Cell cycle } \\
\text { MPHOSPH9-TRIMI3-TADA3L-YWHAQ-ESCO2-DBCI- } \\
\text { E2F6-ERNI-FGF6-SH3BP4-FRAPI-GAS2-APBB2-KRAS- } \\
\text { MAD2LI-MDM2-MLHI-MUTYH-NRAS-NDEI-PPPICB- } \\
\text { CDC37LI-PBK-PRKG2-PTMS-BARDI-CLSPN-NEK4- } \\
\text { YWHAH-MADILI-MCM8-CCNH-PRCI-MTSSI-CUL7- } \\
\text { DCLREIA-CDC34 P = 9.E-03 } \\
\text { Glycolysis } \\
\text { DLAT-ENOI-OGDH-PGAMI-PKM2-UEVLD P = 8.E-03 } \\
\text { Cytokinesis } \\
\text { CECR2-PRCI-ROCK2 P = 7.E-03 } \\
\text { Ceramide metabolism } \\
\text { GALC-PRKAAI-SGPLI P = 7.E-03 } \\
\text { Regulation of protein catabolism } \\
\text { ATEI-MDM2-BARDI P = 2.E-03 }\end{array}$ & $\begin{array}{l}\text { Insulin signalling pathway } \\
\text { PTPNI-PRKAAI-KRAS-FRAPI-PRKABI- } \\
\text { SORBSI-CRK-NRAS } \\
\text { ErbB signalling pathway_- } \\
\text { CAMK2A-JUN-KRAS-FRAPI-PAK7- } \\
\text { SRC-CRK-NRAS- } \\
\text { GnRH signalling pathway } \\
\text { CAMK2A-ADCY3-JUN-KRAS- } \\
\text { CACNAIC-SRC-NRAS } \\
\text { Renal cell carcinoma_- } \\
\text { JUN-SLC2AI-KRAS-PAK7-ARNT-CRK- } \\
\text { NRAS-EGLN3 } \\
\text { Tight junction } \\
\text { JAM3-KRAS-CLDNI6-SRC-MAGII- } \\
\text { NRAS-ACTB } \\
\text { Glioma_- } \\
\text { CAMK2A-KRAS-FRAPI-MDM2-NRAS }\end{array}$ & $\begin{array}{l}\text { Chemokine Signaling } \\
\text { ROCK2-SRC-PLCB4-CAMK2A-NRAS-JUN-MYL2-PPPICB-KRAS P } \\
=3 . E-04 \\
\text { Ephrin Receptor Signaling } \\
\text { MAP3K I4-SRC-NRAS-CREB3-SOS2-KRAS-CRK-ROCK2-AKTI- } \\
\text { SORBSI-EFNBI-ACPI-ARPC4-PRKAAI-PAK7-MAK P = 6.E-04 } \\
\text { B Cell Receptor Signaling } \\
\text { MAP3K I4-FRAPI-AKTI-CAMK2A-NRAS-JUN-MAP3K7-CREB3- } \\
\text { SOS2-PIK3API-KRAS P = 3.E-03 } \\
\text { Estrogen Receptor Signaling } \\
\text { SRC-PRKDC-CCNH-NRAS-SOS2-KRAS-GTF2AI-MED4-ESR2 P = } \\
\text { 3.E-03 } \\
\text { PDGF Signaling } \\
\text { SRC-NRAS-JUN-ACPI-SOS2-KRAS-CRK P = 4.E-03 } \\
\text { Wnt/Î2-catenin Signaling } \\
\text { SRC-AKTI-WIFI-MAP3K7-WNT7B-FZD3-DKK2-MDM2 (includes } \\
\text { EG:4I93)-WNT5B-WNT2-SOX5 (includes EG:6660) P = 6.E-03 } \\
\text { Actin Cytoskeleton Signaling } \\
\text { ABI2-TIAMI-NRAS-MYL2-ACTB-SOS2-PPPICB-KRAS-CRK-FGF6- } \\
\text { ROCK2-ARPC4-PRKAAI-PAK7-MAK P = 6.E-03 } \\
\text { JAK/Stat Signaling } \\
\text { FRAPI-AKTI-NRAS-SOS2-PTPNI-KRAS P = 8.E-03 } \\
\text { Hypoxia Signaling in the Cardiovascular System } \\
\text { AKTI-JUN-COPS5-CREB3-MDM2 (includes EG:4I93)-CDC34- } \\
\text { UBE2I-ARNT } \\
\text { P = 6.E-04 }\end{array}$ \\
\hline $\begin{array}{c}\text { Cluster } 4 \\
273 \text { genes }\end{array}$ & & $\begin{array}{l}\text { TGF.beta signalling pathway } \\
\text { ACVR2A-PPP2R2A-RBLI } \\
\text { Complement and coagulation } \\
\text { cascades } \\
\text { FI3AI-C8B-F8-PLAU } \\
\text { Purine metabolism } \\
\text { ADSL-ITPA-ATIC-POLRIB-POLR3G- } \\
\text { POLR2C } \\
\text { Gap junction } \\
\text { CDC2-PDGFA-MAP2K2-GNAII } \\
\text { RNA_polymerase } \\
\text { POLRIB-POLR3G-POLR2C } \\
\text { Histidine_metabolism } \\
\text { ADSL-GADI-ATIC } \\
\text { Long.term depression } \\
\text { RARB-CASP9-STK4-MAP2K2 } \\
\text { Long.term_potentiation } \\
\text { GRIN2B-GRIN2A-MAP2K2 }\end{array}$ & 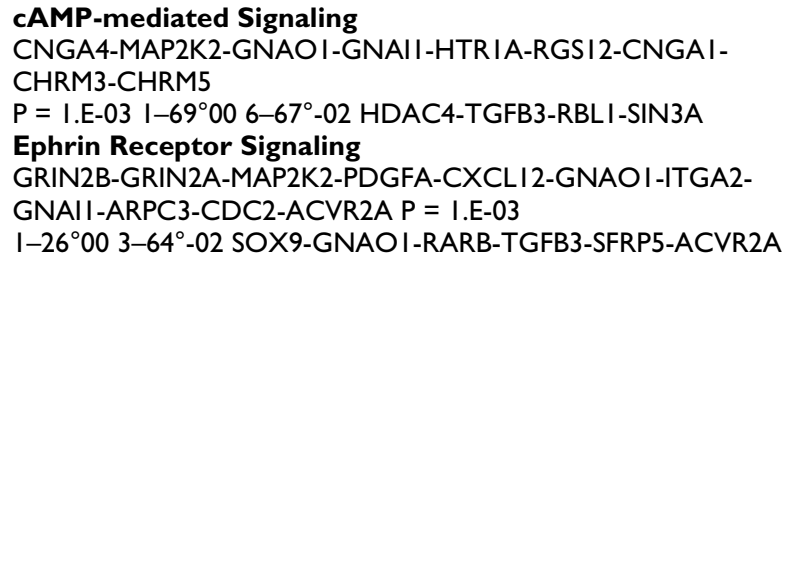 \\
\hline
\end{tabular}

The pathways sub-lined were found in at least two of the three analyses.' Biological process GO terms obtained by the Gene Ontology Tree Machine software (GOTM). Are only indicated the enriched biological process GO terms with a significant level of pvalue $<0.01$ (see Methods) and a minimum of 3 genes associated. ${ }^{2}$ Kegg pathways: are only indicated those with a minimum of 3 genes associated and having a probability to be observed in the cluster 4-fold superior than the probability to obtain it by chance. ${ }^{3}$ Ingenuity pathways: are indicated the top five Canonical pathways associated to each cluster (pvalue $<0.01$ ). Only canonical pathways with at least 3 genes affiliated were conserved. 
Following this global overview of the data, we chose to focus on genes regulated by the first 16 hours of fasting (clusters 1 and 2) that were involved in "lipid biosynthesis", "fatty acid beta-oxidation", "ketogenesis" and "gluconeogenesis". Several genes were chosen for validation of the microarray results using quantitative RT-PCR. A further group of genes encoding FADS1 and FADS2 desaturases and transcriptional factors known to be important regulators of hepatic lipid metabolism were also considered.

\section{Genes involved in fatty acid- and cholesterol-synthesis and in fatty acid beta-oxidation, ketogenesis and gluconeogenesis \\ Validation by $q R T-P C R$}

Twenty four genes involved in peroxisomal or mitochondrial beta-oxidation of fatty acids, in ketogenesis, in gluconeogenesis and in fatty acid and cholesterol synthesis were present on the microarrays, respectively 10, 3, 3, 4 and 4 genes. As indicated in Figure $4-\mathrm{A}$, after $16 \mathrm{~h}$ of fasting, all lipogenic genes and cholesterogenic genes were significantly down-regulated, except $H M G C R$ no regulated and HMGCS1 up-regulated. By contrast, all genes involved in ketogenesis, gluconeogenesis and mitochondrial or peroxisomal fatty acid beta-oxidation were significantly up-regulated, except EHHADH and HMGCS2. The highest amplitudes of up-regulations were observed for CPT1A, PECI, ACAA1, ACOX1, HMGCL, PCK1 ( 2- up to 4 -fold, pval $<10^{-8}$ ). The genes ACLY, FASN, ME1 and SCD were down-regulated by 2 -fold. To confirm these microarray data, 8 of the 21 genes differentially expressed after 16 $\mathrm{h}$ of fasting were analyzed by qRT-PCR (Figure 4-B). The results confirmed the microarray analyses, but higher amplitudes of variation were generally measured by qRTPCR. Notably, the up-regulation of the HMGCS1 gene during fasting was largely confirmed (3-fold by microarray and 10-fold by quantitative RT-PCR). The 3 genes HMGCR, EHHADH and HMGCS2 not found significantly differentially expressed by microarray were analyzed by quantitative RT-PCR as well. EHHADH was up-regulated during fasting ( $16 \mathrm{~h}$ or $48 \mathrm{~h}$ ) and HMGCR down-regulated, as described in mammals. By contrast, HMGCS2 was found significantly up-regulated but only after $16 \mathrm{~h}$ of fasting. Overall these results are consistent with those reported in mammals except for the gene HMGCS1, which could show species specific patterns of regulation.

Expression of genes encoding SREBP-I, PPARa, SREBP-2 and NRIH3 transcription factors

Because Peroxysome Proliferators-Activated Receptor alpha (PPARa), Sterol Regulatory Element Binding Protein 1 and 2 (SREBP1 and SREBP-2) and Nuclear Receptor Subfamily 1, group H, member 3 (NR1H3 also noted LXRa for Liver X receptor alpha), have been identified in mammals as critical transcription factors for the regulation of hepatic fatty acid beta-oxidation, fatty acid synthe- sis or cholesterol metabolism [6], we measured their expression by quantitative RT-PCR (Figure 4-B). PPARa: We observed an up-regulation of PPARa in chicken livers after fasting (3- and 2-fold at Fst 16 and Fst48 states respectively). The correlations at the mRNA level between PPARa and its putative targets in chickens (ACOX1, EHHADH, CPT1, HMGCS2) were significantly high: 0.82 to 0.86 using the qRT-PCR expressions of the 18 chickens in Fed, Fst16 and Fst48 states. Using the 2.1 Washington University assembly of the Gallus gallus genome sequence, the upstream sequences of those genes were screened for a putative PPARa response element (PPRE). As indicated in Table 2, potential PPRE were identified in ACOX1, CPT1 and HMGCS2. SREBP1: The first $16 \mathrm{~h}$ of fasting caused a significant repression of the hepatic expression of SREBP1 (2- and 4-fold for Fst16 and Fst48 states respectively). The correlations between SREBP1 and its putative targets in chickens (ACLY, ACACA, FASN and $S C D)$ at the mRNA level were significantly high ( 0.87 to 0.92 using the 18 chickens in Fed, Fst16 and Fst48 states). SREBP2: The transcriptional factor SREBP2 regulates the expression of many genes involved in cholesterol synthesis. We observed by qRT-PCR a decrease of SREBP2 gene expression after fasting, (4- and 6-fold after $16 \mathrm{~h}$ and $48 \mathrm{~h}$ of fasting) correlated to HMGCR gene expression. Microarray results also indicated a 2-fold decreased expression of genes encoding CYP51A1 (Lanosterol 14alphademethylase) and LSS (Lanosterol synthase), other enzymes involved in cholesterol synthesis. By contrast, HMGCS1 was strongly up-regulated during starvation. NR1H3: NR1H3 mRNA level was significantly increased (by 2-fold) after $16 \mathrm{~h}$ of fasting and remained unchanged after $48 \mathrm{~h}$ whereas genes known to be its direct targets in mammals were down-regulated by fasting. It was the case for the lipogenic genes SREBP1, FASN and SCD and for Cyp7a1 (cholesterol 7 hydroxylase) encoding the rate-limiting enzyme of cholesterol degradation to bile acids.

\section{Expression of genes involved in desaturation of fatty acids}

GO term, IPA and Kegg pathway analyses highlighted SCD which is considered as an enzyme involved in monounsaturated fatty acid synthesis. However, SCD (also named delta9-desaturase) belongs to the fatty acid desaturase family, which also includes FADS1 (delta5-desaturase) and FADS2 (delta6-desaturase), two key enzymes for the production of polyunsaturated fatty acids. We observed that fasting resulted in a 14 - to 18 -fold inhibition of SCD expression (measured by qRT-PCR at $16 \mathrm{~h}$ and 48 h of fasting respectively, Figure 4-B). A significant repression was observed for both FADS1 and FADS2 genes but only after $48 \mathrm{~h}$ of fasting (4- or 6-fold depending on the genes, Figure 4-B). The data show that the expression profiles of SCD gene and the two FADS1 and $F A D S 2$ genes were different in response to fasting in chickens. 


\section{Discussion}

To date few studies have reported global gene expression surveys in chickens. Wang et al [27] provided an analysis of the chicken adipose tissue gene expression profile using a 28 k GeneChip Chicken Genome Array (Affymetrix Inc.). Other hepatic transcriptional analyses have been reported but using only dedicated chicken microarrays: $3.2 \mathrm{~K}$ liver-specific microarray [28,29] or a 323 cDNA microarray [30]. Although microarray studies are more numerous in mammalian species, only few studies have considered global gene expression of the liver tissue in response to fasting. The effect of fasting has been studied in the liver of mice fasted during $24 \mathrm{~h}$ or $48 \mathrm{~h}$ using a 20 K oligo microarray $[10,11]$ and in the liver of rats fasted during $24 \mathrm{~h}$ with a $30 \mathrm{~K}$ oligo-chip [14]. One study was conducted in the liver of pigs fasted during $24 \mathrm{~h}$ which used a 1272 cDNA microarray [12], and more recently one was conducted in the liver of trouts submitted to 3 weeks of food deprivation which used a $16 \mathrm{~K}$ microarray [13]. In the present study, we analyzed the hepatic expression of 13057 genes in 4 week-old chickens, submitted to $16 \mathrm{~h}$ or $48 \mathrm{~h}$ of starvation. Of the 7419 annoted genes on the microarray (e.g. having a human ortholog), we observed 1162 genes with an amplitude of variation higher than $+/-40 \%$ at pvalue below 0.01 (corrected for multiple test). Because our gene selection satisfied the criterion of FDR $<1 \%$ (so only 12 genes were statistically false positives) our results could be considered as reliable; and indeed all the differential genes tested were confirmed by qRT-PCR. It remains, however, that the amplitude of the differences measured by qRT-PCR were generally higher than those measured using microarrays. This may explain why EHHADH, HMGCR and HMGCS2 were observed as differentially expressed by qRT-PCR but not by microarray; and it may suggest that the microarray analyses based on hybridization technique is more hampered by proportion of false negative compared to qRTPCR analyses because of the lack of an amplification step. The list of the 1162 genes differentially expressed in the chicken liver after starvation is available in additional file 1.

The main observation was that a high number of genes were regulated by fasting in chicken liver and in a time dependent manner: the expression of 190 genes was altered by $16 \mathrm{~h}$ of fasting versus that of 777 genes was altered by 48 h. In mouse liver, Bauer et al (2004) [10] made a similar observation (131 genes and 269 genes modulated by $24 \mathrm{~h}$ and $48 \mathrm{~h}$ of fasting respectively) even if the number of differential genes was lower compared to the present study. Another important observation was that the number of genes down-regulated by fasting was higher than the number of genes up-regulated, whatever the duration of fasting ( $16 \mathrm{~h}$ or $48 \mathrm{~h}$ ): 799 genes versus 360 genes respectively. Among the 190 genes annoted as enzymes that represented $16 \%$ of the genes annoted, 136 genes $(72 \%)$ were down-regulated. Numerous reports have shown that birds are relatively resistant to long period of starvation [31-34]. This is the case for chickens which resist to longer period of starvation than mice $[33,34]$. Four week old chickens survive starvation periods of more than 10 days [35], loosing about $37 \%$ of body weight during this period. This suggests that the severity of a $48 \mathrm{~h}$ fasting period is limited. However, our observations suggest a global repression of the cellular activity in response to short-term starvation (16-48 h).

Principal components analysis clearly separated the three nutritional conditions; the most $(80 \%)$ of the differentially expressed genes were correlated with the two principal components and so contributed to distinguish the three states. By a two-way hierarchical clustering analysis, 4 clusters were identified: 277 genes were down-regulated and 95 genes up-regulated after $16 \mathrm{~h}$ of fasting, most of them showing a similar pattern at $48 \mathrm{~h}$ of fasting. A prolonged starvation up to $48 \mathrm{~h}$ repressed 517 and induced 273 gene expressions. We then used the three databases, Gene Ontology, KEGG and INGENUITY to analyze the 4 gene clusters. These databases supply a useful tool for a global biological interpretation of microarray data. We can however notice some contradictions which could be due to the imperfection of these annotations. First, a biological process could be highlighted through genes which are not key regulators of this process but only indirectly involved in it. As an illustration, the "Valine, leucine and isoleucine degradation" process was cited from KEGG and IPA databases in cluster 2 through genes involved in ketogenesis (Table 1) even though the first key enzyme of this pathway, BCAT1 (an aminotransferase) was absent of this cluster and belonged to cluster 1 . Second, the allocation of a gene to a pathway may not always be optimal. For example, Gamma-butyrobetaine dioxygenase (BBOX1, cluster 2), was associated to the "Lysine degradation pathway" in KEGG and IPA databases while this enzyme catalyses carnitine biosynthesis and should therefore be associated to "fatty acid beta-oxidation" process in which carnitine is essential for mitochondrial beta-oxidation [36]. Another limitation may arise from the fact that some particular genes may not be annoted by automatic annotation processes. For instance, the Pyruvate dehydrogenase kinase 4 gene (PDK4 up-regulated after $16 \mathrm{~h}$ of fasting, ) was not cited in the "gluconeogenesis" pathway associated to the cluster 2, whereas PDK4 phosphorylates and inhibits the activity of the pyruvate dehydrogenase complex and thus promotes the conversion of pyruvate into lactate, which is used in the liver for gluconeogenesis. Other genes important in the "lipid biosynthesis" process and associated to cluster 1 were also not highlighted: Insulin receptor Signaling gene (IRS2) or Insulin induced gene (INSIG1) which mediate feedback control of cholesterol 


\begin{tabular}{|c|c|c|c|c|c|c|}
\hline \multicolumn{3}{|l|}{$A$} & \multicolumn{2}{|c|}{ Fst16-Fed } & \multicolumn{2}{|c|}{ Fst48-Fed } \\
\hline $\begin{array}{l}\text { Gene } \\
\text { symbol }\end{array}$ & Gene name & Metabolism & ratio & pvalue & ratio & pvalue \\
\hline SCD & Stearoyl-CoA desaturase (delta-9-desaturase) & Fatty acid synthesis & -1.17 & ** & NS & NS \\
\hline ACLY & ATP citrate lyase & Fatty acid synthesis & -0.99 & *** & -0.57 & ** \\
\hline FASN & Fatty acid synthase & Fatty acid synthesis & -0.95 & *** & NS & NS \\
\hline ME1 & Malic enzyme 1,NADP (+) dependent, cytosolic & Fatty acid synthesis & -0.94 & *** & -0.60 & ** \\
\hline $\mathrm{PECl}$ & Peroxisomal 3.2-trans-enoyl-CoA isomerase & Perox. $\beta$-oxydation & 1.84 & *** & 0.88 & *** \\
\hline ACAA1 & Acetyl-Coenzyme A acyltransferase 1 & Perox. $\beta$-oxydation & 1.21 & *** & 0.93 & *** \\
\hline ACOX1 & Acyl-Coenzyme A oxidase 1, palmitoyl & Perox. $\beta$-oxydation & 1.49 & *** & 0.62 & 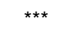 \\
\hline EHHADH & Peroxisomal bifunctional enzyme & Perox. $\beta$-oxydation & NS & NS & NS & NS \\
\hline CPT1A & Carnitine palmitoyltransferase $1 \mathrm{~A}$ (liver) & Mito. $\beta$-oxydation & 2.11 & *** & 0.59 & *** \\
\hline HADHA & 3-ketoacyl-CoA thiolase, alpha subunit & Mito. $\beta$-oxydation & 1.33 & *** & 0.38 & ** \\
\hline ACAA2 & Acetyl-CoA acyltransferase 2 & Mito. $\beta$-oxydation & 0.44 & * & NS & NS \\
\hline ACADL & Acyl-CoA dehydrogenase, long chain & Mito. $\beta$-oxydation & 0.40 & * & 0.49 & *** \\
\hline CRAT & Carnitine acetyltransferase & Mito. $\beta$-oxydation & 0.37 & ** & 0.46 & ** \\
\hline СРT2 & Carnitine palmitoyltransferase II & Mito. $\beta$-oxydation & 0.26 & * & NS & NS \\
\hline PCK1 & Phosphoenolpyruvate carboxykinase, cytosolic & Gluconeogenesis & 1.48 & *** & NS & NS \\
\hline FBP1 & Fructose-1,6-bisphosphatase 1 & Gluconeogenesis & 0.95 & *** & 0.58 & *** \\
\hline FBP2 & Fructose-1,6-bisphosphatase 2 & Gluconeogenesis & 0.74 & *** & 0.53 & *** \\
\hline HMGCL & 3-hydroxy-3-methylglutarate-CoA lyase & Ketogenesis & 2.32 & *** & 0.61 & ** \\
\hline ACAT1 & Acetyl-CoA acetyltransferase 1 & Ketogenesis & 0.69 & *** & 0.37 & ** \\
\hline HMGCS2 & HMG-Coenzyme A synthase 2 (mitochondrial) & Ketogenesis & NS & NS & NS & NS \\
\hline HMGCS1 & HMG-Coenzyme A synthase 1 (soluble) & Cholesterol synthesis & 1.63 & *** & NS & NS \\
\hline HMGCR & HMG-Coenzyme A reductase & Cholesterol synthesis & NS & NS & NS & NS \\
\hline LSS & Lanosterol synthase & Cholesterol synthesis & -0.69 & *** & -0.76 & *** \\
\hline CYP51A1 & Lanosterol 14-alpha demethylase & Cholesterol synthesis & -0.80 & ** & NS & NS \\
\hline
\end{tabular}

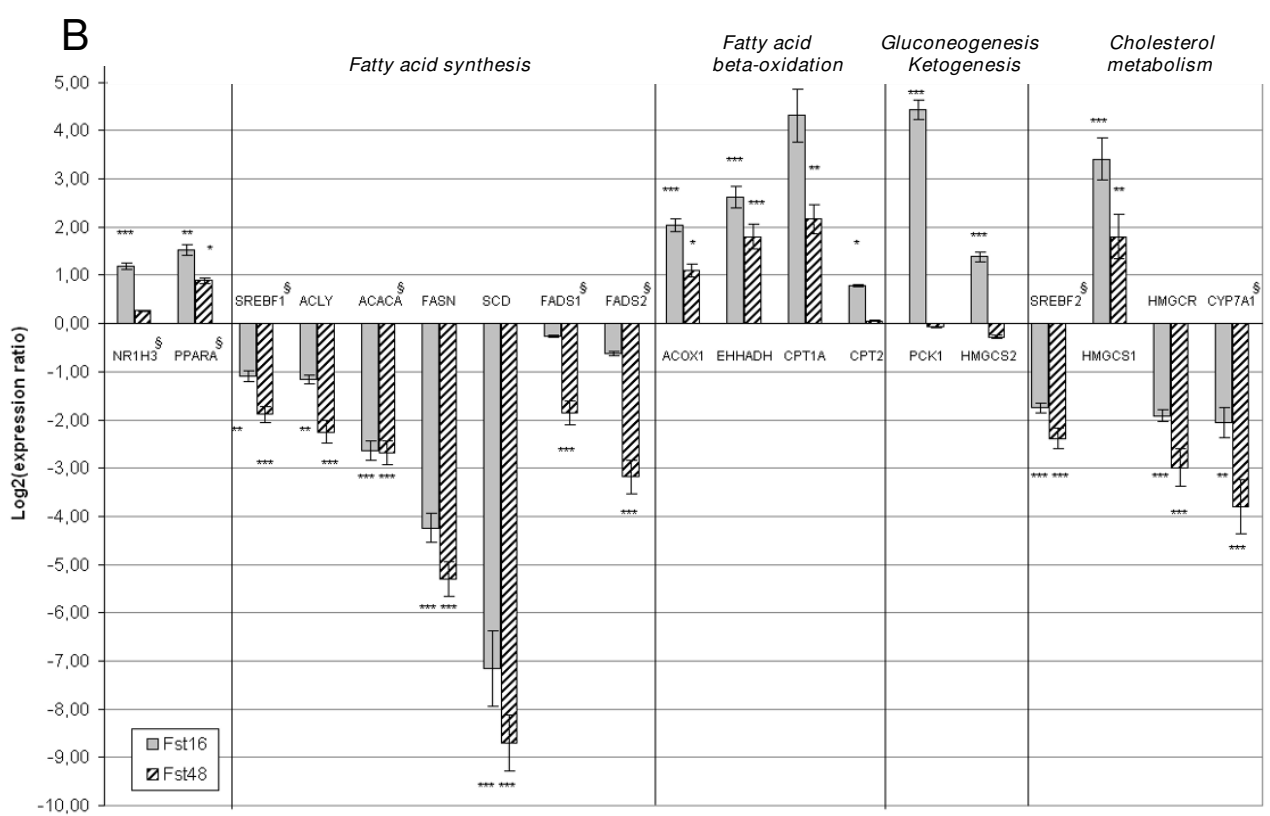

\section{Figure 4}

Identification of differentially expressed genes involved in fatty acid synthesis, beta-oxidation, ketogenesis, gluconeogenesis and cholesterol metabolism. A: Expression of genes present on microarray and analyzed by microarray procedure. Gene symbol: HGNC Hugo abbreviation of the human ortholog of the Gallus gallus gene represented by the oligo spotted on microarray. Results were expressed as a $\log 2$ ratio of the gene expression between fasted and fed states ("Fst 16 Fed" or "Fst48-Fed" contrasts). Genes in gold were analyzed by qRT-PCR (see B). P values were corrected by Benjamini-Hochberg (see Methods). * pvalue $<0.05$, ** pvalue $<0.01$, *** pvalue $<0.00$ I, NS: non-significant. B: Validation of microarray results by $q R T$-PCR. PCRs were realized in triplicate with $\mathrm{SyBr}$ Green and specific primers for each gene (See Table I). I8S ribosomal RNA was used as reference. Results were expressed as a log2 ratio of the gene expression for the two "Fst16-Fed" and "Fst48Fed" contrasts. Statistical significance is indicated as following: *pvalue $<0.05$, ** pvalue $<0.01$, ****pvalue $<0.001$. Genes not analyzed by microarray procedure are indicated with $\S$ 
and fatty acid synthesis by controlling SREBP cleavageactivating protein (SCAP) involved in the regulation of cleavage of Sterol response element binding proteins (SREBP1 and SREBP2). Considering these imperfections, the annotation results require an expert biological knowledge to validate them and draw up precise comments and this is a limit to the full interpretation of pangenomic microarray data. However, the use of such databases, in particular when several are combined as in the present study, remains a first and useful step for a global biological interpretation as it allows highlighting the major pathways involved.

In the present study, the GO, KEGG and IPA annotation results taken together are complementary and allow us to draw up the following overview about the general biological mechanisms associated with each cluster. First, and as could be expected, they point out to an alteration of lipid and acetyl-CoA metabolisms during the first $16 \mathrm{~h}$ of fasting (clusters 1 and 2): lipogenic and cholesterogenic genes were down-regulated whereas genes involved in fatty acid beta-oxidation, ketogenesis, gluconeogenesis and fatty acid activation or transport were up-regulated. These results are in agreement with the previously reported alterations of glucose and lipid metabolisms in response to short-term starvation in rodents $[10,14,37,38]$, pigs [12] and chickens $[15,19]$. Second and less expected, they highlight a number of cell signalling pathways which would seem to be altered between $16 \mathrm{~h}$ and $48 \mathrm{~h}$ of fasting (clusters 3 and 4). Notably, genes in the "Insulin signalling cascade" would seem to be repressed whereas genes in the "cAMP-mediated signalling" pathway would seem to be enhanced. More than ten signalling response pathways were identified in cluster 3 (Table 1), suggesting a general repression of signalling pathways at $48 \mathrm{~h}$ of starvation. Many genes associated with these pathways are implicated in cellular responses, also involved in cell proliferation and differentiation. Precise comments about them would need an expert biological knowledge.

Because PPARa, SREBP1, SREBP-2 and NR1H3 have been identified in mammals as critical transcription factors for the regulation of fatty acid beta-oxidation, fatty acid synthesis or cholesterol metabolism, we examined their expressions by qRT-PCR.

Definite proof that PPARa plays a key role in the up-regulation of fatty acid beta-oxidation, ketogenesis and gluconeogenesis in the liver during starvation comes from several studies using PPARa-null (KO) mice. Using a geneby-gene approach, these studies identified PPARa target genes [7-9,39]. Short-term fasting (12-72 h) in KO mice

Table 2: PPRE prediction in Gallus gallus HMGCS2, CPTIA and ACOXI genomic DNA sequences

\begin{tabular}{|c|c|c|c|c|c|c|}
\hline Genes & Species & Ensembl ID & PPRE Pattern & Location & Strand & Methods \\
\hline \multirow{4}{*}{ HMGCS2 } & RNO & Rodriguez et al. 1994 [79] & GGGCCAaAGGTCT & Promoter region & & \\
\hline & GGA & ENSGALG00000002960 & GGGCCAaAGGTCC & -530 & + & STAN/PATSER \\
\hline & HSA & ENSG00000 I 34240 & GGGTCAaAGGGCT & -118 & + & STAN \\
\hline & MUS & ENSMUSG00000027875 & GGGCCAaAGGGAT & -104 & $\mathrm{RC}$ & STAN \\
\hline \multirow[t]{4}{*}{ CPTIA } & HSA/MUS/RNO & Napal et al., 2005 [80] & AGGGGAaAGGTCA & Intronic region betv & reen exon & 1 and exon 2 \\
\hline & GGA & ENSGALG00000007077 & AGGGAAaAGGGCA & 4964 & + & STAN \\
\hline & HSA & ENSG00000II0090 & AGGGGAaAGGTCA & 2426 & + & STAN \\
\hline & MUS & ENSMUSG00000024900 & AGGGGAaAGGTTA & 2180 & $\mathrm{RC}$ & STAN \\
\hline \multirow[t]{8}{*}{ ACOXI } & MUS & Tugwood et al., 1992 [8।] & AGGACAaAGGTCA & Promoter region & & \\
\hline & GGA & ENSGALG00000002159 & - & - & - & \\
\hline & HSA & ENSG00000161533 & - & - & - & \\
\hline & MUS & ENSMUSG00000020777 & - & - & - & \\
\hline & RNO & Krey et al., I 995 [82] & AGGTAGaAGGTCA & Promoter region & & \\
\hline & GGA & ENSGALG00000002159 & AGGAAGaAAGTCA & -3931 & + & STAN/PATSER \\
\hline & HSA & ENSG00000I61533 & - & - & - & STAN \\
\hline & MUS & ENSMUSG00000020777 & AGGTAAaAGGTCA & 52 & + & STAN \\
\hline
\end{tabular}

PPRE patterns used for the research is indicated in bold with the reference associated. GGA: Gallus gallus; HSA: Homo sapiens; MUS: Mus musculus. Nucleic acids in red indicate conserved nucleic acids with the PPREs used for the research. Location: genomic location refers to the start of the Ensembl first exon (+I). Strand: "RC" indicates that the sequence is reverse complemented compared to the genomic sequence displayed at that location, otherwise a " + " is indicated. STAN or PASTER indicates that the PPRE has been identified either by STAN or PATSER softwares respectively (see Methods). For the ACOXI gene, despite previous results indicating PPRE in the Mus musculus promoting DNA sequence [8I], we cannot found any PPRE with the STAN procedure in any species. We used another PPRE pattern [82] identified in the Rattus norvegicus DNA sequence. This pattern allowed us to identify potential PPRE in Gallus gallus and Mus musculus sequences. The absence of result in the Homo sapiens sequence was consistent with the literature [78]. 
resulted in hepatic steatosis and hypoketonemia. Our observations also suggest a critical role of PPARa in the up-regulation of these metabolisms in chicken liver in response to fasting. First, we observed a marked induction of PPARa expression after $16 \mathrm{~h}$ and $48 \mathrm{~h}$ of fasting, confirming earlier results by Cogburn et al [23] in the same species. Second, we identified potential PPRE in avian genes ACOX1, CPT1 and HMGCS2 involved respectively in peroxisomal and mitochondrial beta-oxidation and ketogenesis. Third we observed a significant correlation between PPAR $a$ and ACOX1, EHHADH, CPT1 mRNA levels. Fourth, within the 15 genes showing the highest level of induction following $16 \mathrm{~h}$ of fasting (see additional file 1 : cluster 2), we found 8 genes involved in fatty acid betaoxidation (PECI, ACAA1, ACOX1, CPT1A, HADHA), ketogenesis (HMGCL, ACAT1), or gluconeogenesis (PCK1), the majority being direct targets of PPARa.

By contrast, hepatic expression of SREBP1 (encoding a key transcription factor controlling the expression of lipogenic enzymes in mammals) decreased after the first $16 \mathrm{~h}$ of fasting. We also observed a significant correlation between SREBP1 mRNA levels and those of their putative target genes ACLY, ACACA, FASN and SCD. These results suggest a key role of SREBP1 in the regulation of fatty acid synthesis in chickens as already suggested by others studies carried out on the same species $[40,41]$ and demonstrated in rodents $[37,38,42]$ using $24 \mathrm{~h}$ of fasting.

SREBP2 regulates the expression of many genes involved in cholesterol synthesis. Cholesterol is an essential component of animal cell membranes, and its concentration is tightly controlled by a feedback system that operates at transcriptional and posttranscriptional levels [43]. In the present study, we observed a decrease of SREBP-2, HMGCR, LSS and CYP51A1 expressions during food deprivation. HMGCR is considered as the rate limiting enzyme of cholesterol synthesis. These results suggest a decrease of cholesterol synthesis in response to starvation in chickens, as already reported in rodents after $24 \mathrm{~h}$ or 48 $\mathrm{h}$ of fasting $[10,14,44]$. However, HMGCS1 gene another gene involved in cholesterogenesis exhibited a strikingly different pattern of expression, with a marked induction at $16 \mathrm{~h}$ of fasting which is contrast with the repression of HMGCS1 expression observed during starvation in mice and pigs $[10,12]$. Two distinct genes condense acetyl-CoA with acetoacetyl-CoA to form HMG-CoA in the cell, the first one HMGCS2, located in mitochondria is involved in ketogenesis, whereas the second one, HMGCS1 controls cholesterogenesis in the cytosol. Like in other species, these two genes have been characterized in avian species [45], allowing us to design gene specific oligonucleotides. Four isoforms of the HMGCS1 enzyme have been described in chicken liver [46] while only one was characterized in rat liver. The specific role of the 4 isozymes and the mechanism to generate them are not clear and must be clarified to better understand the species difference in HMGCS1 expression.

NR1H3 (named also LXRa) is a transcription factor that belongs to the nuclear hormone receptor family and was first discovered as playing a critical role in cholesterol homeostasis and bile acid metabolism through the regulation of Cyp7a1 (cholesterol 7 hydroxylase), the rate-limiting enzyme of cholesterol degradation to bile acids [47] It is also a master lipogenic transcription factor, directly regulating SREBP1 [48,49], FASN [50], SCD [51] and ChREBP genes [52]. We therefore expected its expression profile to parallel to those of its potential avian targets during the feeding-fasting transition. Curiously, we observed that NR1H3 mRNA level was increased at $16 \mathrm{~h}$ of fasting and returned to fed levels by $48 \mathrm{~h}$. This result is consistent with a previous study conducted in rodents: rats fasted for $24 \mathrm{~h}$ increased LXRa mRNA level by 3 -fold [53]. The role of NR1H3 during starvation remains to be elucidated.

We then studied the effects of fasting on the hepatic expressions of the three genes encoding the desaturases SCD, FADS1 and FADS2. SCD (also named delta9-desaturase) catalyzes the synthesis of monounsaturated fatty acids (MUFAs) whereas FADS1 (delta5-desaturase) and FADS2 (delta6-desaturase) are two key enzymes for the synthesis of highly polyunsaturated fatty acids (HUFA). All three mammalian desaturases are induced at the mRNA levels by PPARa [54-56] and SREBP1 [57-59]. This dual activation is a specificity of the desaturases compared to the enzymes of beta-oxydation or lipogenesis which are exclusively regulated by either PPARa or SREBP1 (for review, see [60]). In rodents, SCD gene activity is completely repressed during fasting, like the activity of other lipogenic genes (ACLY, ACACA, FASN) and SREBP1 $[37,38,61]$. We observed the same regulation for the chicken SCD gene: the first $16 \mathrm{~h}$ of fasting resulted in a 14fold inhibition of its expression and lasted up to $48 \mathrm{~h}$ of fasting. Because of their common regulation by SREBP1 and PPARa, similar modulations could be expected for the three genes in response to fasting. By contrast, we observed that FADS1 and FADS2 genes were only significantly repressed after $48 \mathrm{~h}$ of fasting (4- or 6-fold). In pig liver, SCD and FADS1 were down-regulated after $24 \mathrm{~h}$ of fasting [12]. To our knowledge, no data about the FADS1 and FADS2 expression modulation in response to fasting are available in rodents. This difference of modulation between SCD gene and the two genes FADS1 and FADS2 in response to short-fasting suggest an additional regulatory mechanism between SCD1 and these two latter genes. Such a hypothesis was already done by Matsuzaka et al [58], from their data obtained during fasting-refeeding treatment in which no changes of FADS1 and FADS2 
expression contrary to the lipogenic genes was observed. So, these two enzymes which play crucial roles in the production of HUFA, might have an important role in fasted state because HUFA were reported to inhibit SREBP-1 activity by multiple mechanism [62-65] and to be ligands of PPARa.

\section{Conclusion}

In the present study, we successfully used a chicken $20 \mathrm{~K}$ oligo microarrays to analyze the alteration of hepatic gene expression profile upon starvation. We identified 1162 genes differentially expressed between the $16 \mathrm{~h}$ or $48 \mathrm{~h}$ fasting states and the fed state. We provide a valuable and publicly available resource of genes profiles altered during the first $48 \mathrm{~h}$ of starvation in chicken liver. After $16 \mathrm{~h}$ of fasting we observed an up-regulation of genes involved in fatty acid oxidation, ketogenesis, gluconeogenesis and a down-regulation of genes involved in fatty acid and cholesterol synthesis, which is consistent with earlier results obtained in mammals. After $48 \mathrm{~h}$ of fasting, when the number of genes showing an altered expression was much higher (about 3.5-fold higher), the annotation data suggest a repression of genes involved in numerous signalling pathways. As a whole, we observed that more genes were down-regulated than up-regulated in response to starvation. The expression profiles of candidate genes encoding key transcription factors and enzymes involved in lipid metabolism but not present on the microarray were evaluated by qRT-PCR. The results were similar to those reported in mammals except for the gene HMGCS1, which was induced at $16 \mathrm{~h}$ of fasting in chicken liver and repressed in mouse and pig liver. Our data also suggest that the genes SCD, FADS1 and FADS2 encoding different desaturases are regulated differently during fasting and $\mathrm{NR} 1 \mathrm{H} 3$ is up-regulated at $16 \mathrm{~h}$ of fasting while one of its target, SREBP1 is down-regulated. Further studies should be performed to precise their role in the complex regulation array of lipid metabolism.

\section{Methods}

\section{Animals and experimental procedures}

Male broiler chicks obtained from a commercial hatchery were bred at INRA, UR083, Recherches Avicoles, F-37380 Nouzilly in accordance with European Union guidelines for animal care and under the authorization 006621 delivered to M.J. Duclos by the French Ministry of Agriculture. All birds were reared up to 1 week of age in floor pens, then raised for 2 weeks in cages under " $14 \mathrm{~h}$ light:10 h darkness" cycles. During this period, they were fed a balanced starter diet (12.12 MJ metabolized energy/kg containing $22 \%$ crude protein). At 3 weeks of age, the chickens were weighed and assigned to seven experimental groups ( $\mathrm{n}=10$ per group), equalizing body weight and variance between groups. One week later, each group was submitted to one of the following treatments: fed ad libitum (Fed), fasted for $16 \mathrm{~h}$ or $48 \mathrm{~h}$ (Fst16 and Fst48, respectively), and four other treatments not analyzed in this present study [66]. All birds were given free access to water at all time. Following sacrifice, liver were collected, quickly frozen into liquid nitrogen and stored at $-80^{\circ} \mathrm{C}$ until molecular analysis.

\section{RNA isolation}

Total RNA was extracted with TRIzol $^{\circledR}$ reagent (Invitrogen, Cergy Pontoise, France) according to the manufacturer's instructions. Quality and concentration of extracted RNA were assessed using a 2100 Bioanalyzer (Agilent Technologies, Massy, France).

\section{Array slides and annotation}

The chicken $20 \mathrm{~K}$ array was obtained from ARK-Genomics (Roslin institute-UK: http://www.ark-genomics.org). The array design has been published in the ArrayExpress repository with the accession A-MEXP-820 [67] and in Gene Expression Omnibus with the platform name GPL5480 [68].

Briefly, the DNA microarray was produced from 20,460 oligonucleotides (whose the size varies from 60 to 75 nucleotides) designed using the OligoArray 2.0 software against the chicken ENSEMBL transcripts. The transcripts were selected from the chicken genome draft available in december 2004 and extensive matching of the UMIST and DT40 full length EST's with the TIGR clusters. Because the $20 \mathrm{~K}$ oligonucleotide set was defined in 2004-2005 from heterogeneous data sources, we checked the quality of the previously designed oligos, comparing them with the chromosomes of the 2.1 Washington University assembly of the chicken sequence genome [69]. The comparison was made using NCBI Blast with a $75 \%$ similarity threshold over 50 base pairs. Then for each high scoring pair (HSP) we retrieved the transcripts corresponding to the location using the Ensembl API (version Ensembl 43). An oligonucleotide had to be in a unique gene (even if it was spanning 2 exons) to be selected for further analyses. The corresponding annotations were then retrieved from Ensembl using the blast HSP coordinates. As results, among the 20460 gene-oligonucleotides, 13057 were identified as aligning with a unique coding region in the chicken genome sequence. As we retrieved an Ensembl gene name and/or a GO biological process term for only $32 \%$ of the 13057 oligo sub-set, we decided to rely on human orthologs (according to the "one to one" criteria of ENSEMBL annotation) which could be identified for $81 \%$ of the 13057 oligonucleotides, allowing to retrieve HGNC-HUGO gene symbol for the majority of them (70\% of $81 \%$ of 13057 ). The annotations obtained by a bioinformatics procedure developed by SIGENAE (INRA) are available on the web site: http://www.sigenae.org[69]. Finally, of the 13057 oligonucleotides, 7419 presented a validated HUGO gene symbol from which we could extract more GO terms from GOA human annotation 
database using the two softwares "Hugo my Genes" and "GOret" developed by the Rennes transcriptome platform: http://ouestgenopuces.univ-rennes1.fr.

\section{Microarray procedures}

$m R N A$ labelling and hybridization

Five $\mu \mathrm{g}$ of each RNA sample were reverse-transcribed and Cy5 fluorescent-labelled using the ChipShot ${ }^{\mathrm{TM}}$ Direct Labeling kit (Promega, Charbonnieres, France). Each Cy5labelled RNA was hybridized to the microarray with a same Cy3-labelled reference probe according to the Transcriptome-Biochips Platform of Genopole "Toulouse Midi-Pyrénées" (France) procedure. Briefly, experiments were carried out with an automatic hybridization chamber (Discovery from Ventana Medical System, Inc). Prehybridization was carried out with a freshly prepared solution of $1 \%$ BSA, $2 \times$ SSC, $0.1 \%$ SDS over $30 \mathrm{~min}$ at $42^{\circ} \mathrm{C}$. After automatic washing according to manufacturer's instructions, the slides were hybridized for $8 \mathrm{~h}$ in $200 \mu$ of ChipHybe ${ }^{\mathrm{TM}}$ buffer (Ventana Medical System, Inc) containing $10 \mu \mathrm{l}$ of labelled cDNA purified. After hybridization, the slides were washed twice for $2 \mathrm{~min}$ in $2 \times \mathrm{SSC} / 0.1 \%(\mathrm{v} / \mathrm{v}) \mathrm{SDS}$, and for $2 \mathrm{~min}$ in $0.1 \times \mathrm{SSC}$. We finally obtained 9, 7 and 7 microarrays respectively for the three nutritional conditions Fed, Fst16 and Fst48. For each gene, the fluorescence ratio reflected the relative abundance of the mRNA of interest in each experimental sample compared with the same reference mRNA. The reference allowed thus to take into account an eventual "spot $\times$ array" interaction.

\section{Data acquisition}

Detection of the fluorescence signals was made with a laser scanner (GenePix 4000A from Axon Instrument, CA) keeping a constant PMT gain for each channel. The images were then analyzed with GenepixPro 4.0 software (Axon instruments, Inc., Union City, CA). Row data file for each array containing all measured values were stored in genepix files compatible with the LIMMA library of R-project statistical and Bioconductor environment [70] which was used for the normalization and the analysis of the data.

\section{Filtering for data normalization}

For the normalization step, data were filtered according to 3 criterions: i) the genepix flag criterion automatically performed by GenepixPro 4.0 [71], ii) the SNR (Signal to Noise Ratio) provided also by GenepixPro and which was set to 2, iii) a asymmetry criterion of the spot which was set to $20 \%$. For all microarrays, the mean percentages of spots discarded for the genepix flag, SNR and asymmetry criterions were $3.3 \%, 10.4 \%$ and $3.7 \%$ respectively. It was $16 \%$ for the three criterion taken together, showing the good quality of all technical procedures from slide production to labelling and hybridization. However, 5 arrays ( 3 and 2 in Fed and Fst16 conditions respectively) which presented a percentage of spots not conformed to the SNR criterion higher than 50\% were excluded from subsequent analysis. These 5 microarrays were discarded among a set of 60 microarrays corresponding to a larger experimental design with 6 treatments, confirming a global good quality of the technical procedures. The homogeneity of the background was systematically checked on each microarray by the boxplot and imageplot procedures of the LIMMA package. We finally analyzed 18 microarrays: 6, 5 and 7 microarrays for Fed, Fst16 and Fst 48 conditions respectively.

\section{Data normalization}

The ratio Cy5/Cy3 used was expressed as the Log2 of the ratio of median pixel intensity of the two red and green spots. Log2 median ratio values were then normalized on each individual array (ratio centered on zero) according to the hypothesis that the majority of gene expressions do not differ between two samples. The centering was performed by "Lowess fitness" [72] to take into account the intensity dependence of the fluorescence bias. Only the array spots conform to the filtering step were used for the normalization.

\section{Data analysis}

All data analyses were performed using the R project statistical and Bioconductor environment [70]. Analysis of variance using the "eBayes" procedure [24] and analysis of contrasts were performed with LIMMA library appropriated to bi-color genepix files. Two-way Hierarchical Cluster Analysis (HCA) was performed using hclust function with "1-cor" as distance and "ward" as aggregation criterion; "heatmap" function was used to generate images. Principal Component Analysis (PCA) was performed with FactoMiner library. In this study, we were interested in comparing the two Fst16 and Fst48 conditions with the Fed state. The significance of gene expression differences between the nutritional conditions was assayed by analysis of variance followed by an analysis of the two contrasts "Fst16-Fed" and "Fst48-Fed". Because of the high test number (13057) needing an appropriated control of the false positive rate, the pvalue of each gene for each contrast was corrected according to the false discovery rate (FDR) procedure of Benjamini-Hochberg [25]; the FDR is the expected proportion of erroneously rejected null hypotheses among the rejected ones. Gene expression difference was declared significant if its corrected pvalue was $\mathrm{p}<0.01$. Results were further filtered by retaining only the genes exhibiting at least an amplitude of variation higher than $+/-40 \%$ between two nutritional states of interest $(($ absolute $(\log 2($ ratio $))>0.485)$.

\section{Gene ontology, KEGG and IPA analyses}

Gene ontology (GO) constitutes a controlled vocabulary of about 20,000 terms organized in three independent 
Table 3: Selected qRT-PCR primer sequences and accession numbers

\begin{tabular}{|c|c|c|c|}
\hline Gene symbol & Gene name & $\begin{array}{l}\text { Ensembl or Gene bank } \\
\text { Accession number }\end{array}$ & Primer sequence (forward/reverse) \\
\hline ACACA & Acetyl-Coenzyme A carboxylase alpha & ENSGALG00000005439 & $\begin{array}{l}\text { GAGGAGGGAAGGGAATTAGGAA } \\
\text { CCAAGTGGCGGGACTGTT }\end{array}$ \\
\hline ACOXI & Acyl-Coenzyme A oxidase I & ENSGALG00000002159 & $\begin{array}{l}\text { TCATCCGGTCTCTGATTGTAGGA } \\
\text { GCACTATAGCGGATGGCAATG }\end{array}$ \\
\hline ACLY & ATP citrate lyase & ENSGALG00000003475 & $\begin{array}{l}\text { GGCGTGAATGAACTGGCTAAC } \\
\text { TAGTCTTGGCATAGTCATAGGTCTGTTG }\end{array}$ \\
\hline CPTIA & Carnitine palmitoyltransferase IA & ENSGALG00000007077 & $\begin{array}{l}\text { CCCTGAAAATGCTGCTTTCCTA } \\
\text { TGGTGCCTGCAGAAAGTTTG }\end{array}$ \\
\hline CPT2 & Carnitine palmitoyltransferase II & ENSGALG000000I $068 \mathrm{I}$ & $\begin{array}{l}\text { CCTGAACGCCCAGAAACCT } \\
\text { CCCTTTTCAAACTGATGAGCAAGT }\end{array}$ \\
\hline CYP7AI & Cytochrome P450, family 7, subfamily A, polypeptide I & ENSGALG000000I 5432 & $\begin{array}{l}\text { TGATGACATGGAAAAAGCAAAGA } \\
\text { CCAAAAAGTAGCAGGAATGGTGTT }\end{array}$ \\
\hline EHHADH & Peroxisomal bifunctional enzyme & ENSGALG00000006680 & $\begin{array}{l}\text { TCATAGAAAGGAGCGAGAAGC } \\
\text { AGCAGGAACCCCAACCAGT }\end{array}$ \\
\hline FADSI & Fatty acid desaturase I & ENSGALG00000007I 27 & $\begin{array}{l}\text { CAGCACCACGCGAAACC } \\
\text { TCTACAGAGAGCTTCTTTCCCAAAG }\end{array}$ \\
\hline FADS2 & Fatty acid desaturase 2 & ENSGALG00000007/78 & $\begin{array}{l}\text { CCATGATCAAGCGCAGGTT } \\
\text { ATGTATGTGATGAAATAGCGCATGTAG }\end{array}$ \\
\hline FASN & Fatty acid synthase & ENSGALG00000002747 & $\begin{array}{l}\text { TGAAGGACCTTATCGCATTGC } \\
\text { GCATGGGAAGCATTTTGTTGT }\end{array}$ \\
\hline HMGCSI & Hydroxymethylglutaryl-CoA synthase, cytoplasmic & ENSGALG000000I4862 & $\begin{array}{l}\text { GCTGGTGCTGTTGCTATGCT } \\
\text { TGTCTGTCCCCTCTTTTTGC }\end{array}$ \\
\hline HMGCS2 & Hydroxymethylglutaryl-CoA synthase, mitochondrial & ENSGALG00000002960 & $\begin{array}{l}\text { GGTGGTGTGTGGGGACAT } \\
\text { GGTAGCACTGGATGGAGAGG }\end{array}$ \\
\hline HMGCR & 3-hydroxy-3-methylglutaryl- Coenzyme A reductase & ENSGALG000000I4948 & $\begin{array}{l}\text { CTGGGTTTGGTTCTTGTTCA } \\
\text { ATTCGGTCTCTGCTTGTTCA }\end{array}$ \\
\hline $\mathrm{NRIH} 3$ & $\begin{array}{l}\text { Nuclear receptor subfamily I, group } H \text {, member } 3 \\
(L X R \alpha)\end{array}$ & ENSGALG00000008202 & $\begin{array}{l}\text { TCCCACTCAACTCAGCACAC } \\
\text { CAGACTTCATTTCCCAGCATC }\end{array}$ \\
\hline PCKI & Phosphoenolpyruvate carboxykinase, cytosolic & ENSGALG00000007636 & $\begin{array}{l}\text { CTGCTGGTGTGCCTCTTGTA } \\
\text { TTCCCTTGGCTGTCTTTCC }\end{array}$ \\
\hline PPARA & Peroxisome proliferative activated receptor, alpha & ENSGALG00000022985 & $\begin{array}{l}\text { AGCATCCAGTCCTTCATCCA } \\
\text { AAAAACCCTTACAACCTTCACAA }\end{array}$ \\
\hline SCD & $\begin{array}{l}\text { Stearoyl-CoA desaturase } \\
\text { (delta-9-desaturase) }\end{array}$ & ENSGALG00000005739 & $\begin{array}{l}\text { TTTGGCAATCGGCCGTAT } \\
\text { TGGTAGTTGTGGAAACCTTCTCCTA }\end{array}$ \\
\hline SREBFI & Sterol regulatory element binding protein I & gb:AY029224 & $\begin{array}{l}\text { GTCGGCGATCCTGAGGAA } \\
\text { CTCTTCTGCACGGCCATCTT }\end{array}$ \\
\hline SREBF2 & Sterol regulatory element binding protein 2 & ENSGALG00000011916 & $\begin{array}{l}\text { GGCTGGCTTCTCCCCCTAT } \\
\text { GTTCATCCTTAACCTTTGCATCAT }\end{array}$ \\
\hline
\end{tabular}

Genes in bold were present on the microarray. 
hierarchies for cellular components, molecular functions, and biological processes [73]. Gene ontology analyses of clusters identified by HCA were performed using the Gene Ontology Tree Machine (GOTM) software [74]. Hypergeometric test was used as the statistical method to select enriched biological process GO terms for each cluster compared to the GO terms of the annoted genes present on the microarray (7419 genes). The biological process GO terms were considered as enriched for a level of pvalue $<0.01$. The biological interpretation of the gene clusters were further completed by KEGG annotation [26] and Ingenuity Pathway Analysis, the latter software using various annotation data (IPA, Ingenuity Systems Inc., Redwood City, CA). Were only conserved Kegg pathways with a minimum of 3 genes associated and having a probability to be observed in the cluster 4-fold superior than the probability to obtain it by chance. For Ingenuity pathways, we only reported in the present study the top five canonical pathways having a pvalue $<0.01$ and at least 3 genes affiliated.

\section{Real time quantitative RT-PCR (qRT-PCR) assay}

A set of 11 genes present on the microarray was chosen for confirmation by quantitative RT-PCR, 8 of which were significantly differentially expressed between the $16 \mathrm{~h}$ fasting state and the Fed state. In addition, 8 candidate genes not present on the microarray were also measured by qRTPCR (Figure 4).

Reverse transcription (RT) was carried out using the highcapacity cDNA archive kit (Applied Biosystems, Foster City, CA) according to the manufacturer's protocol. Briefly, $200 \mu \mathrm{L}$ of each reaction mixture containing $20 \mu \mathrm{L}$ of $10 \times$ RT buffer, $8 \mu \mathrm{L}$ of $25 \mathrm{X}$ dNTPs, $20 \mu \mathrm{L}$ of $10 \mathrm{X}$ random primers, $10 \mu \mathrm{L}$ of MultiScribe Reverse Transcriptase (50 U/ $\mu \mathrm{L})$, and total RNA $(10 \mu \mathrm{g})$ was incubated for $10 \mathrm{~min}$ at $25^{\circ} \mathrm{C}$ followed by $2 \mathrm{~h}$ at $37^{\circ} \mathrm{C}$. A $1 / 10$ or $1 / 20$ dilution, dependant on the gene, of each RT reaction was further used for real time quantitative PCR (qPCR). cDNA samples were mixed with $20 \mu \mathrm{l}$ ABsolute SYBR Green Mix (Abgene, UK) and 300, 450 or $600 \mathrm{nM}$, according to the gene, of specific reverse and forward primers (Table 3 ). Reaction mixtures were incubated in an iCycler iQ Multicolour Real-Time PCR Detector (Bio-Rad, Marne la Coquette, France) programmed to conduct one cycle $\left(95^{\circ} \mathrm{C}\right.$ for $\left.15 \mathrm{~min}\right)$ and 40 cycles $\left(95^{\circ} \mathrm{C}\right.$ for $15 \mathrm{~s}$ and $59^{\circ} \mathrm{C}$ for $45 \mathrm{~s}$ ). A melting curve program was then performed for each gene to check the presence of an unique product with specific melting temperature. For each sample and each gene, PCR runs were performed in triplicates. For each gene, serial PCR reactions constructed with 2-fold serial dilutions from a pool of the cDNA samples were systematically added on each microplate for the calibration curve and determination of the amplification rate $(\mathrm{R})$ of the Taq polymerase. For all genes including $18 S$, the amplification rates were in a range of $99 \%$ to $100 \%$ and could be considered as equal to 1 . So, for a same sample, the gene expression level could be normalized relative to the $18 \mathrm{~S}$ expression level as follows: Gene normalized CT $=$ CTgene - CT18S $=\Delta$ Ct. The significance of expression differences between nutritional states were analyzed by analysis of variance and analysis of contrasts on the basis of the gene normalized CT values using AOV package of $\mathrm{R}$ environment. For each gene, the N-fold gene expression difference between two conditions ( 1 versus 2 ) was expressed as: Fold change $=2 \exp (-\Delta \Delta \mathrm{Ct})$ with $\Delta \Delta \mathrm{Ct}=\operatorname{mean}(\Delta \mathrm{Ct}) 2-$ mean $(\Delta \mathrm{Ct}) 1$, where $(\Delta \mathrm{Ct}) \mathrm{i}$ are the mean of the gene normalized Ct of the different samples of the condition $\mathrm{i}$.

\section{PPRE prediction in the HMGCS2, CPTIA and ACOXI genomic DNA sequences}

Several custom PERL scripts were developped to automate the PPRE detection procedure. Gallus gallus (GGA) genomic DNA sequences (including $5000 \mathrm{bp}$ upstream and 3000 bp downstream sequence from the start of the first exon) were extracted from the Ensembl website by the GGA Ensembl ID. The orthologous genomic sequences of Homo sapiens and Mus musculus were automatically extracted (1-to-1 ortholog type) using the Compara API [75]. The DNA sequences were analyzed by the STAN [76] and the PATSER software [77]. The PPRE patterns used for every gene were designed from previous results found in the literature [78-82]. For STAN PPRE detection, one degree of freedom were applied on each part of the DR1 (e.g., for HMGCS2, the PPRE pattern syntax was: "AGACCT": 1, 1...1, "TGGCCC": 1 , see Nicolas et al. [76] for details on the syntax used in STAN). For PATSER detection, Positional Weight Matrix (PWM) were generated using CONSENSUS software [77] using PPRE sequences described by previous studies. Raw results obtained by both softwares were post-analyzed by another custom PERL script.

\section{Abbreviations}

PPARa: Peroxysome Proliferators-Activated Receptor alpha; FADS1: Fatty Acid Desaturase 1 (delta5-desaturase); FADS2: Fatty Acid Desaturase 2 (delta6-desaturase); SCD: Stearoyl CoA Desaturase 1 (delta9-desaturase); SREBP1 and 2: Sterol Regulatory Element Binding Protein 1 and 2; NR1H3: Nuclear Receptor Subfamily 1, group H, member 3 (noted LXRa for Liver X receptor alpha); HMGCS1: 3-Hydroxy-3-MethylGlutaryl-CoA Synthase 1; ME: Malic Enzyme; ACLY: ATP Citrate Lyase; ACACA: Acetyl CoA Carboxylase; CPT1A: Carnitine PalmitoylTransferase 1A; EHHADH: Enoyl-CoA Hydratase/3HydroxyAcyl CoA DeHydrogenase; PEPCK: PhosphoEnolPyruvate CarboxyKinase; PPRE: PPAR Element; GO: Gene Ontology; KEGG: Kyoto Encyclopedia of Genes and Genomes; qRT-PCR: quantitative Reverse Transcription- 
Polymerase Chain Reaction; HGNC: HUGO Gene Nomenclature Committee; FDR: False Discovery Rate.

\section{Authors' contributions}

$\mathrm{CD}$ and SL were responsible for generating the gene expression data and for interpretation and analysis of the results. CD and CB carried out the qRT-PCR experiments. $\mathrm{PB}, \mathrm{FH}$ and SL performed the statistical analyses with R. FL performed the PPRE prediction. MJD designed and provided the animal experimental design, contributed advice on the analysis and critically reviewed the manuscript. FM, CK, MA and SL contributed to the annotations of the $20 \mathrm{~K}$ microarray. PLR and SL defined the microarray experimental design. CD and SL drafted the manuscript. $\mathrm{MD}, \mathrm{CDi}$, and CB reviewed the manuscript. SL proposed and supervised the research. All authors read and approved the final manuscript.

\section{Additional material}

\section{Additional file 1}

List of the 1162 genes differentially expressed in the chicken liver after $16 \mathrm{~h}$ or $48 \mathrm{~h}$ of starvation ordered according to their HCA cluster. These 1162 genes $i)$ were significantly differentially expressed between fasting and fed states (pvalue $<0.01$ ), ii) exhibited at least an expression difference between two conditions exceeding an absolute 1.4 fold ratio, iii) were annoted through their human ortholog. The selected 0.01 pvalue that was corrected according to the false discovery rate (FDR) of Benjamini-Hochberg [25] ensures in average a number of false positive of 12 genes in the selected gene set. For each cluster, genes were ordered by decreasing $\log 2$ (ratio) of the "Fst16-Fed" contrast for the clusters 1 and 2 and then of the "Fst48-Fed" contrast for the clusters 3 and 4.

Click here for file

[http://www.biomedcentral.com/content/supplementary/14712164-9-611-S1.xls]

\section{Acknowledgements}

This research was supported by the French Ministry for Research through an $\mathrm{ACl}$ IMPBio program based on interdisciplinarity, by the Institut National de la Recherche Agronomique (INRA) and by the Direction Générale de I'Enseignement et de la Recherche of the Ministry of Agriculture. PB is a Ph.D. fellow supported by INRA. We acknowledge Lidwine Trouilhe and Véronique Leberre from the transcriptomic platform of Toulouse for performing the hybridizations, Richard Talbot and Alison Downing from ArkGenomics for providing the microarrays and Cecile Duby and Estelle Godet for participating to RNA extraction or QRT-PCR.

\section{References}

I. Seitz HJ, Muller MJ, Krone W, Tarnowski W: Coordinate control of intermediary metabolism in rat liver by the insulin/glucagon ratio during starvation and after glucose refeeding. Regulatory significance of long-chain acyl-CoA and cyclic AMP. Arch Biochem Biophys 1977, 1 83(2):647-663.

2. Christiansen RZ: Regulation of palmitate metabolism by carnitine and glucagon in hepatocytes isolated from fasted and carbohydrate refed rats. Biochim Biophys Acta 1977, 488(2):249-262.

3. Parvin R, Pande SV: Enhancement of mitochondrial carnitine and carnitine acylcarnitine translocase-mediated transport of fatty acids into liver mitochondria under ketogenic conditions. J Biol Chem 1979, 254( ( 2):5423-5429.

4. Bergseth S, Lund H, Poisson JP, Bremer J, Davis-Van Thienen W, Davis EJ: Carnitine palmitoyltransferase: activation and inactivation in liver mitochondria from fed, fasted, hypo- and hyperthyroid rats. Biochim Biophys Acta 1986, 876(3):55I-558.

5. Berghe $G$ van den: The role of the liver in metabolic homeostasis: implications for inborn errors of metabolism. J Inherit Metab Dis 199I, 14(4):407-420.

6. Desvergne B, Michalik L, Wahli W: Transcriptional regulation of metabolism. Physiol Rev 2006, 86(2):465-5 4.

7. Kroetz DL, Yook P, Costet P, Bianchi P, Pineau T: Peroxisome proliferator-activated receptor alpha controls the hepatic CYP4A induction adaptive response to starvation and diabetes. J Biol Chem 1998, 273(47):3 I58I-3I589.

8. Kersten S, Seydoux J, Peters JM, Gonzalez FJ, Desvergne B, Wahli W: Peroxisome proliferator-activated receptor alpha mediates the adaptive response to fasting. J Clin Invest 1999, 103(II): I 489-1498.

9. Leone TC, Weinheimer CJ, Kelly DP: A critical role for the peroxisome proliferator-activated receptor alpha (PPARalpha) in the cellular fasting response: the PPARalpha-null mouse as a model of fatty acid oxidation disorders. Proc Natl Acad Sci USA 1999, 96(13):7473-7478.

10. Bauer M, Hamm AC, Bonaus M, Jacob A, Jaekel J, Schorle H, Pankratz $M J$, Katzenberger JD: Starvation response in mouse liver shows strong correlation with life-span-prolonging processes. Physiol Genomics 2004, I 7(2):230-244.

II. Rakhshandehroo M, Sanderson LM, Matilainen M, Stienstra R, Carlberg C, de Groot PJ, Muller M, Kersten S: Comprehensive Analysis of PPARalpha-Dependent Regulation of Hepatic Lipid Metabolism by Expression Profiling. PPAR Res 2007, 2007:26839.

12. Cheon Y, Nara TY, Band MR, Beever JE, Wallig MA, Nakamura MT: Induction of overlapping genes by fasting and a peroxisome proliferator in pigs: evidence of functional PPARalpha in nonproliferating species. Am J Physiol Regul Integr Comp Physiol 2005, 288(6): RI525-1535.

13. Salem M, Silverstein J, Rexroad CE 3rd, Yao J: Effect of starvation on global gene expression and proteolysis in rainbow trout (Oncorhynchus mykiss). BMC Genomics 2007, 8:328.

14. Nakai $Y$, Hashida H, Kadota K, Minami M, Shimizu K, Matsumoto I, $\mathrm{Kato} H$, Abe $\mathrm{K}$ : Up-regulation of genes related to the ubiquitin-proteasome system in the brown adipose tissue of 24-hfasted rats. Biosci Biotechnol Biochem 2008, 72(I): $139-148$.

15. Calabotta DF, Cherry JA, Siegel PB, Jones DE: Lipogenesis and lipolysis in fed and fasted chicks from high and low body weight lines. Poult Sci 1985, 64(4):700-704.

16. Skiba-Cassy S, Collin A, Chartrin P, Medale F, Simon J, Duclos MJ, Tesseraud S: Chicken liver and muscle carnitine palmitoyltransferase I: nutritional regulation of messengers. Comp Biochem Physiol B Biochem Mol Biol 2007, I 47(2):278-287.

17. Brady LJ, Romsos DR, Brady PS, Bergen WG, Leveille GA: The effects of fasting on body composition, glucose turnover, enzymes and metabolites in the chicken. J Nutr 1978, I 08(4):648-657.

18. Rosebrough RW, McMurtry JP, Steele NC: Protein and energy relations in the broiler chicken. Chronic or acute effects of alternating protein or intermittent feeding regimens on broiler lipid metabolism. Br J Nutr 1989, 6 I (2):223-233.

19. Leveille GA, Romsos DR, Yeh Y, O'Hea EK: Lipid biosynthesis in the chick. A consideration of site of synthesis, influence of diet and possible regulatory mechanisms. Poult Sci 1975, 54(4): 1075-1093.

20. Griffin HD, Guo K, Windsor D, Butterwith SC: Adipose tissue lipogenesis and fat deposition in leaner broiler chickens. J Nutr 1992, I 22(2):363-368.

21. O'Hea EK, Leveille GA: Lipogenesis in isolated adipose tissue of the domestic chick (Gallus domesticus). Comp Biochem Physiol 1968, 26(I):III-120.

22. Hanson RW, Reshef L: Regulation of phosphoenolpyruvate carboxykinase (GTP) gene expression. Annu Rev Biochem 1997, 66:58I-6II.

23. Cogburn LA, Porter TE, Duclos MJ, Simon J, Burgess SC, Zhu JJ, Cheng $\mathrm{HH}$, Dodgson JB, Burnside J: Functional genomics of the chicken-a model organism. Poult Sci 2007, 86(1 0):2059-2094. 
24. Smyth GK: Linear models and empirical bayes methods for assessing differential expression in microarray experiments. Stat Appl Genet Mol Biol 2004, 3:Article3.

25. Benjamini $Y$, Hochberg $Y$ : Controlling the false discovery rate: a practical and powerful approach to multiple testing. J Roy Stat Soc B 1995, 57:289-300.

26. Kanehisa $M$, Goto $S$, Hattori $M$, Aoki-Kinoshita KF, Itoh $M$, Kawashima S, Katayama T, Araki M, Hirakawa M: From genomics to chemical genomics: new developments in KEGG. Nucleic Acids Res 2006:D354-357.

27. Wang HB, Li H, Wang QG, Zhang XY, Wang SZ, Wang YX, Wang $X P$ : Profiling of chicken adipose tissue gene expression by genome array. BMC Genomics 2007, 8: 193.

28. Cogburn LA, Wang X, Carre W, Rejto L, Aggrey SE, Duclos MJ, Simon J, Porter TE: Functional genomics in chickens: development of integrated-systems microarrays for transcriptional profiling and discovery of regulatory pathways. Comp Funct Genom 2004, 5:253-26I.

29. Duclos MJ, Wang X, Carre W, Rejto L, Simon J, Cogburn LA: Nutritional regulation of global gene expression in chicken liver during fasting and re-feeding. Plant Animal Genom XII Conf: 2004; San Diego, CA 2004.

30. Bourneuf E, Herault F, Chicault C, Carre W, Assaf S, Monnier A, Mottier S, Lagarrigue S, Douaire M, Mosser J, et al.: Microarray analysis of differential gene expression in the liver of lean and fat chickens. Gene 2006, 372:162-170.

31. Hazelwood RL: The intermediary metabolism of birds. Volume 2. New York: Academic Press; 1972.

32. Webster $A B$ : Physiology and behavior of the hen during induced molt. Poult Sci 2003, 82(6):992-1002.

33. Bierer BW, Eleazer TH, Roebuck DE: Effect of Feed and Water Deprivation on Chickens, Turkeys, and Laboratory Mammals. Poult Sci 1965, 44:768-773.

34. Cuendet GS, Loten EG, Cameron DP, Renold AE, Marliss EB: Hormone-substrate responses to total fasting in lean and obese mice. Am J Physiol 1975, 228(I):276-283.

35. Bierer BW, Eleazer TH, Barnett BD: The effect of feed and water deprivation on water and feed consumption, body weight and mortality in broiler chickens of various ages. Poult Sci 1966, 45: 1045-1050.

36. van Vlies N, Ferdinandusse S, Turkenburg M, Wanders RJ, Vaz FM: PPAR alpha-activation results in enhanced carnitine biosynthesis and OCTN2-mediated hepatic carnitine accumulation. Biochim Biophys Acta 2007, I 767(9): I I 34- I I 42.

37. Shimano $\mathrm{H}$, Yahagi $N$, Amemiya-Kudo $M$, Hasty AH, Osuga J, Tamura Y, Shionoiri F, lizuka Y, Ohashi K, Harada K, et al.: Sterol regulatory element-binding protein-I as a key transcription factor for nutritional induction of lipogenic enzyme genes. I Biol Chem 1999, 274(50):35832-35839.

38. Horton JD, Bashmakov Y, Shimomura I, Shimano H: Regulation of sterol regulatory element binding proteins in livers of fasted and refed mice. Proc Natl Acad Sci USA 1998, 95( I I):5987-5992.

39. Hashimoto T, Cook WS, Qi C, Yeldandi AV, Reddy JK, Rao MS Defect in peroxisome proliferator-activated receptor alphainducible fatty acid oxidation determines the severity of hepatic steatosis in response to fasting. I Biol Chem 2000, 275(37):28918-28928.

40. Gondret F, Ferre P, Dugail I: ADD-I/SREBP-I is a major determinant of tissue differential lipogenic capacity in mammalian and avian species. J Lipid Res 200I, 42(I): I06-II3.

41. Assaf S, Hazard D, Pitel F, Morisson M, Alizadeh M, Gondret F, Diot $C$, Vignal A, Douaire $M$, Lagarrigue S: Cloning of cDNA encoding the nuclear form of chicken sterol response element binding protein-2 (SREBP-2), chromosomal localization, and tissue expression of chicken SREBP-I and -2 genes. Poult Sci 2003, 82(I):54-6I

42. Kim JB, Sarraf P, Wright M, Yao KM, Mueller E, Solanes G, Lowell BB, Spiegelman BM: Nutritional and insulin regulation of fatty acid synthetase and leptin gene expression through ADDI/ SREBPI. I Clin Invest 1998, I 0 I (I): I-9.

43. Goldstein JL, DeBose-Boyd RA, Brown MS: Protein sensors for membrane sterols. Cell 2006, I 24(I):35-46

44. Tomkins GM, Chaikoff IL: Cholesterol synthesis by liver. I. Influence of fasting and of diet. J Biol Chem 1952, I 96(2):569-573.

45. Kattar-Cooley PA, Wang HH, Mende-Mueller LM, Miziorko HM: Avian liver 3-hydroxy-3-methylglutaryl-CoA synthase: dis- tinct genes encode the cholesterogenic and ketogenic isozymes. Arch Biochem Biophys 1990, 283(2):523-529.

46. Clinkenbeard KD, Sugiyama T, Reed WD, Lane MD: Cytoplasmic 3Hydroxy-3methylglutaryl Coenzyme A Synthase from liver. J Biol Chem 1975, 250(8):3 I 24-3 I 35.

47. Chiang JY, Kimmel R, Stroup D: Regulation of cholesterol 7alphahydroxylase gene (CYP7AI) transcription by the liver orphan receptor (LXRalpha). Gene 200I, 262(I-2):257-265.

48. Repa JJ, Liang G, Ou J, Bashmakov Y, Lobaccaro JM, Shimomura I, Shan B, Brown MS, Goldstein JL, Mangelsdorf DJ: Regulation of mouse sterol regulatory element-binding protein- I c gene (SREBPIc) by oxysterol receptors, LXRalpha and LXRbeta. Genes Dev 2000, 14(22):2819-2830.

49. Yoshikawa T, Shimano H, Amemiya-Kudo M, Yahagi N, Hasty AH, Matsuzaka T, Okazaki H, Tamura Y, lizuka $Y$, Ohashi $K$, et al:: Identification of liver $X$ receptor-retinoid $X$ receptor as an activator of the sterol regulatory element-binding protein I $c$ gene promoter. Mol Cell Biol 200I, 2 I (9):299I-3000.

50. Joseph SB, Laffitte BA, Patel PH, Watson MA, Matsukuma KE, Walczak R, Collins JL, Osborne TF, Tontonoz P: Direct and indirect mechanisms for regulation of fatty acid synthase gene expression by liver $X$ receptors. J Biol Chem 2002, 277(13): I1019-11025.

51. Chu K, Miyazaki M, Man WC, Ntambi JM: Stearoyl-coenzyme A desaturase I deficiency protects against hypertriglyceridemia and increases plasma high-density lipoprotein cholesterol induced by liver $X$ receptor activation. Mol Cell Biol 2006, 26( I 8):6786-6798

52. Cha JY, Repa J]: The liver $\mathbf{X}$ receptor $(\mathbf{L X R})$ and hepatic lipogenesis. The carbohydrate-response element-binding protein is a target gene of LXR. I Biol Chem 2007, 282(I):743-75 I

53. Tobin KA, Steineger HH, Alberti S, Spydevold O, Auwerx J, Gustafsson JA, Nebb HI: Cross-talk between fatty acid and cholesterol metabolism mediated by liver $\mathbf{X}$ receptor-alpha. Mol Endocrinol 2000, I 4(5):74l-752

54. Tang C, Cho HP, Nakamura MT, Clarke SD: Regulation of human delta-6 desaturase gene transcription: identification of a functional direct repeat-I element. I Lipid Res 2003, 44(4):686-695.

55. Guillou H, Martin P, Jan S, D'Andrea S, Roulet A, Catheline D, Rioux $V$, Pineau $T$, Legrand $P$ : Comparative effect of fenofibrate on hepatic desaturases in wild-type and peroxisome proliferator-activated receptor alpha-deficient mice. Lipids 2002 , 37(10):981-989.

56. Miller CW, Ntambi JM: Peroxisome proliferators induce mouse liver stearoyl-CoA desaturase I gene expression. Proc Natl Acad Sci USA 1996, 93( I 8):9443-9448.

57. Nara TY, He WS, Tang C, Clarke SD, Nakamura MT: The E-box like sterol regulatory element mediates the suppression of human Delta-6 desaturase gene by highly unsaturated fatty acids. Biochem Biophys Res Commun 2002, 296(I): I II-II7.

58. Matsuzaka T, Shimano H, Yahagi N, Amemiya-Kudo M, Yoshikawa T, Hasty $\mathrm{AH}$, Tamura $\mathrm{Y}$, Osuga J, Okazaki H, lizuka $\mathrm{Y}$, et al.: Dual regulation of mouse Delta(5)- and Delta(6)-desaturase gene expression by SREBP-I and PPARalpha. J Lipid Res 2002, 43(I): 107-I I4.

59. Tabor DE, Kim JB, Spiegelman BM, Edwards PA: Identification of conserved cis-elements and transcription factors required for sterol-regulated transcription of stearoyl-CoA desaturase I and 2. J Biol Chem 1999, 274(29):20603-20610.

60. Nakamura MT, Nara TY: Structure, function, and dietary regulation of delta6, delta5, and delta9 desaturases. Annu Rev Nutr 2004, 24:345-376.

6I. Liang G, Yang J, Horton JD, Hammer RE, Goldstein JL, Brown MS Diminished hepatic response to fasting/refeeding and liver $X$ receptor agonists in mice with selective deficiency of sterol regulatory element-binding protein-Ic. J Biol Chem 2002, 277( I I):9520-9528.

62. Xu J, Teran-Garcia M, Park JH, Nakamura MT, Clarke SD: Polyunsaturated fatty acids suppress hepatic sterol regulatory element-binding protein-I expression by accelerating transcript decay. J Biol Chem 2001, 276(I3):9800-9807.

63. Xu J, Nakamura MT, Cho HP, Clarke SD: Sterol regulatory element binding protein-I expression is suppressed by dietary polyunsaturated fatty acids. A mechanism for the coordinate 
suppression of lipogenic genes by polyunsaturated fats. I Biol Chem 1999, 274(33):23577-23583.

64. Yahagi N, Shimano $H$, Hasty AH, Amemiya-Kudo M, Okazaki $H$, Tamura Y, lizuka Y, Shionoiri F, Ohashi K, Osuga J, et al.: A crucial role of sterol regulatory element-binding protein- $I$ in the regulation of lipogenic gene expression by polyunsaturated fatty acids. J Biol Chem 1999, 274(50):35840-35844.

65. Kim HJ, Takahashi M, Ezaki O: Fish oil feeding decreases mature sterol regulatory element-binding protein I (SREBP-I) by down-regulation of SREBP-I c mRNA in mouse liver. A possible mechanism for down-regulation of lipogenic enzyme mRNAs. J Biol Chem 1999, 274(36):25892-25898.

66. Guernec A, Chevalier B, Duclos MJ: Nutrient supply enhances both IGF-I and MSTN mRNA levels in chicken skeletal muscle. Domest Anim Endocrinol 2004, 26(2): | 43-I54.

67. ArrayExpress [http://www.ebi.ac.uk/microarray-as/aer/]

68. Gene expression omnibus [http://www.ncbi.nlm.nih.gov/ projects/geo/]

69. Klopp C, Moreews F, Aubry M, Lagarrigue S: Contribution To The Annotations Of The Chicken 20 K Oligo Microarray Of ARKGenomics. Plant \& Animal Genomes XVI Conference: January I2-16 2008; San Diego, CA 2008.

70. Bioconductor [http://www.bioconductor.org/]

71. Genepix User's guide and tutorial [http://microar ray.okstate.edu/files/GenePix Pro.pdf]

72. Yang YH, Dudoit S, Luu P, Lin DM, Peng V, Ngai J, Speed TP: Normalization for cDNA microarray data: a robust composite method addressing single and multiple slide systematic variation. Nucleic Acids Res 2002, 30(4):e I5.

73. Ashburner M, Ball CA, Blake JA, Botstein D, Butler H, Cherry JM, Davis AP, Dolinski K, Dwight SS, Eppig JT, et al:: Gene ontology: tool for the unification of biology. The Gene Ontology Consortium. Nat Genet 2000, 25(I):25-29.

74. Zhang B, Schmoyer D, Kirov S, Snoddy J: GOTree Machine (GOTM): a web-based platform for interpreting sets of interesting genes using Gene Ontology hierarchies. BMC Bioinformatics 2004, 5: 16

75. Ensembl Compara API [http://www.ensembl.org/info/using/api/ compara/index.html]

76. Nicolas J, Durand P, Ranchy G, Tempel S, Valin AS: Suffix-tree analyser (STAN): looking for nucleotidic and peptidic patterns in chromosomes. Bioinformatics 2005, 2 I (24):4408-44I0.

77. Hertz GZ, Stormo GD: Identifying DNA and protein patterns with statistically significant alignments of multiple sequences. Bioinformatics 1999, 15(7-8):563-577.

78. Lemay DG, Hwang DH: Genome-wide identification of peroxisome proliferator response elements using integrated computational genomics. J Lipid Res 2006, 47(7): I583- 1587.

79. Rodriguez JC, Gil-Gomez G, Hegardt FG, Haro D: Peroxisome proliferator-activated receptor mediates induction of the mitochondrial 3-hydroxy-3-methylglutaryl-CoA synthase gene by fatty acids. J Biol Chem 1994, 269(29): I8767-18772.

80. Napal L, Marrero PF, Haro D: An intronic peroxisome proliferator-activated receptor-binding sequence mediates fatty acid induction of the human carnitine palmitoyltransferase IA. Mol Biol 2005, 354(4):75I-759.

8I. Tugwood JD, Issemann I, Anderson RG, Bundell KR, McPheat WL, Green S: The mouse peroxisome proliferator activated receptor recognizes a response element in the 5' flanking sequence of the rat acyl CoA oxidase gene. Embo J 1992, II (2):433-439.

82. Krey G, Mahfoudi A, Wahli W: Functional interactions of peroxisome proliferator-activated receptor, retinoid-X receptor and $\mathrm{SpI}$ in the transcriptional regulation of the acyl-coenzyme-A oxidase promoter. Mol Endocrinol 1995, 9(2):219-231.
Publish with Bio Med Central and every scientist can read your work free of charge

"BioMed Central will be the most significant development for disseminating the results of biomedical research in our lifetime. "

Sir Paul Nurse, Cancer Research UK

Your research papers will be:

- available free of charge to the entire biomedical community

- peer reviewed and published immediately upon acceptance

- cited in PubMed and archived on PubMed Central

- yours - you keep the copyright
BioMedcentral 